Portland State University

PDXScholar

6-14-1985

\title{
The Communication of Wellness Concepts Interculturally in an Alaskan Health-Care Context
}

Janet A. Allan

Portland State University

Follow this and additional works at: https://pdxscholar.library.pdx.edu/open_access_etds

Part of the Health Communication Commons, and the International and Intercultural Communication Commons

Let us know how access to this document benefits you.

\section{Recommended Citation}

Allan, Janet A., "The Communication of Wellness Concepts Interculturally in an Alaskan Health-Care Context" (1985). Dissertations and Theses. Paper 3427.

https://doi.org/10.15760/etd.5306

This Thesis is brought to you for free and open access. It has been accepted for inclusion in Dissertations and Theses by an authorized administrator of PDXScholar. Please contact us if we can make this document more accessible: pdxscholar@pdx.edu. 
AN ABSTRACT OF THE THESIS OF Janet A. Allan for the Master of Science in Speech Communication presented June 14, 1985. Title: The Communication of Wellness Concepts Interculturally: In an Alaskan Health-Care Context

APPROVED BY MEMBERS OF THE THESIS COMMITTEE:
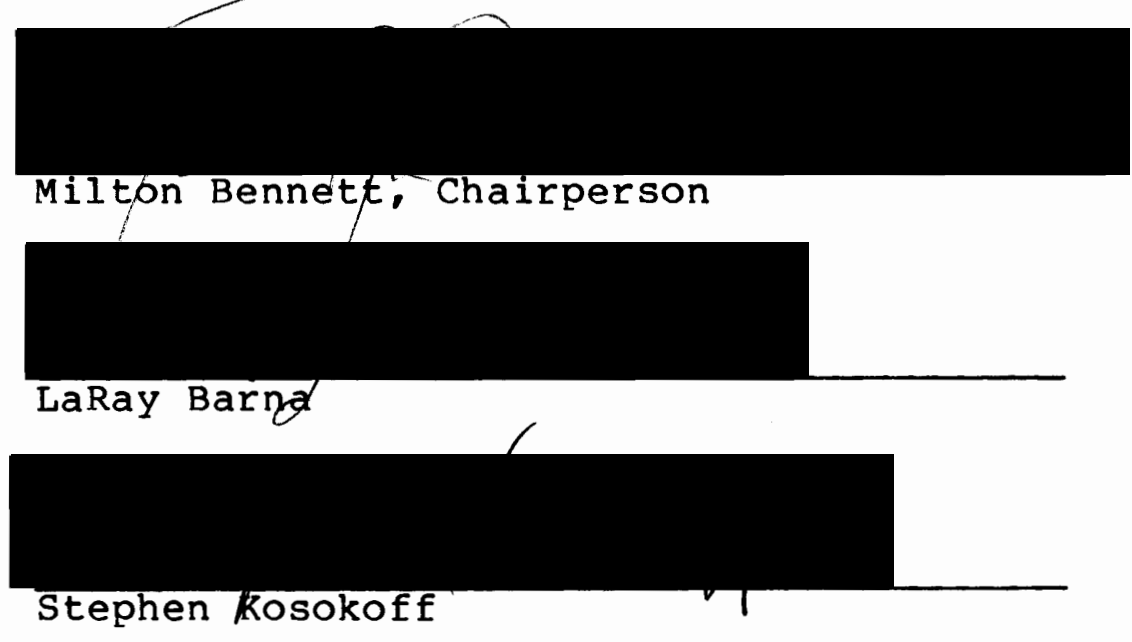

A review of the literature on cross-cultural health care reveals an agreement that health care should "fit" the cultural values and beliefs of the people it serves. However, few authors provide theories that could be applied to overcoming obstacles that surface in the context of cultural difference.

The purpose of this study is to investigate in what ways cultural value differences between Alaskan Native clients and non-Native health professionals affect the communicating of "wellness" concepts. Specifically, this 
study focuses on possible difference in the cultural value orientation of "Man's Relationship to Health."

The major research proposition asserts that Native cultural values underlying health perceptions and behaviors differ from those of non-Natives and that these differences create obstacles to the communication of health/wellness concepts. Specifically, the research proposition asserts that Natives' perceptions regarding who or what controls their health differs from that of non-Natives and that this difference will affect the communication between the two groups.

Theoretical background in the fields of cultural values, the intercultural perspective for communication, wellness approaches to health, wellness within Native culture, and the notion of health locus of control is provided as a framework for addressing the many variables that affect the communication of wellness.

In order to obtain data necessary to address the major research proposition, the following questions were asked: 1) In what ways has the transition from traditional to modern life-styles affected Native cultural values; 2) How do Natives and non-Natives differ in their responses to the question of what controls health; and 3) What should non-Native health professionals know about Native clients in order to be effective counselors.

Utilizing the descriptive method for data collection, both oral interviews and a written instrument measuring 
"Health Locus of Control" were included. Thirty subjects included twenty Natives and ten non-Natives. The twenty Natives were administered the author-generated interview questions (modified with suggestions of five Native pretest subjects). Of this Native group ten were health providers and were also given the written instrument. The ten nonNatives were health providers and they too completed the written instrument.

A t-test was performed on the results of the Health Locus of Control instrument. Although not statistically significant, the differences between the two groups were suggestive of definite value orientation differences, Natives proving to be more internally oriented than nonNatives.

A thematic analysis was undertaken to identify and evaluate themes generated by the interview questions. This data was also used to cross-validate the written instrument results.

Both the interview and written instrument data suggested that Native people had a strong belief in selfresponsibility for their own health and that they experienced communication problems that resulted from culturespecific differences between the two groups.

Information from this study provided methodological suggestions that may prove valuable for future research in this area. 


\section{THE COMMUNICATION OF WELLNESS CONCEPTS \\ INTERCULTURALLY: IN AN ALASKAN \\ HEALTH-CARE CONTEXT}

$$
\text { by }
$$

Janet Ann Allan

A thesis submitted in partial fulfillment of the requirements for the degree of

Master of Science

in

Speech Communication

Portland State University

1985 
TO THE OFFICE OF GRADUATE STUDIES AND RESEARCH:

The members of the Committee approve the thesis of Janet A. Allan presented June 14, 1985.

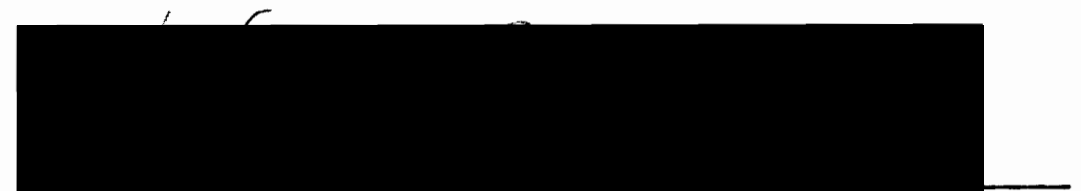

Milton Bennett, Chairperson

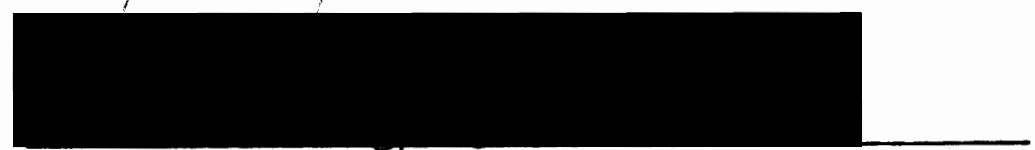

LaRay Barna

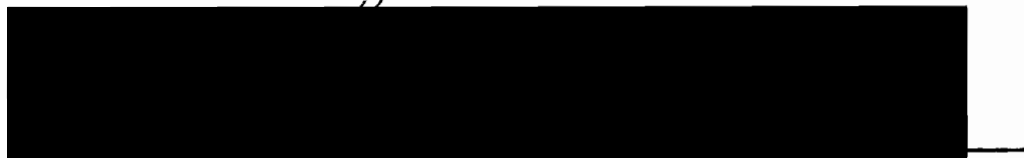

Stephen/Rosokoff

\section{APPROVED :}

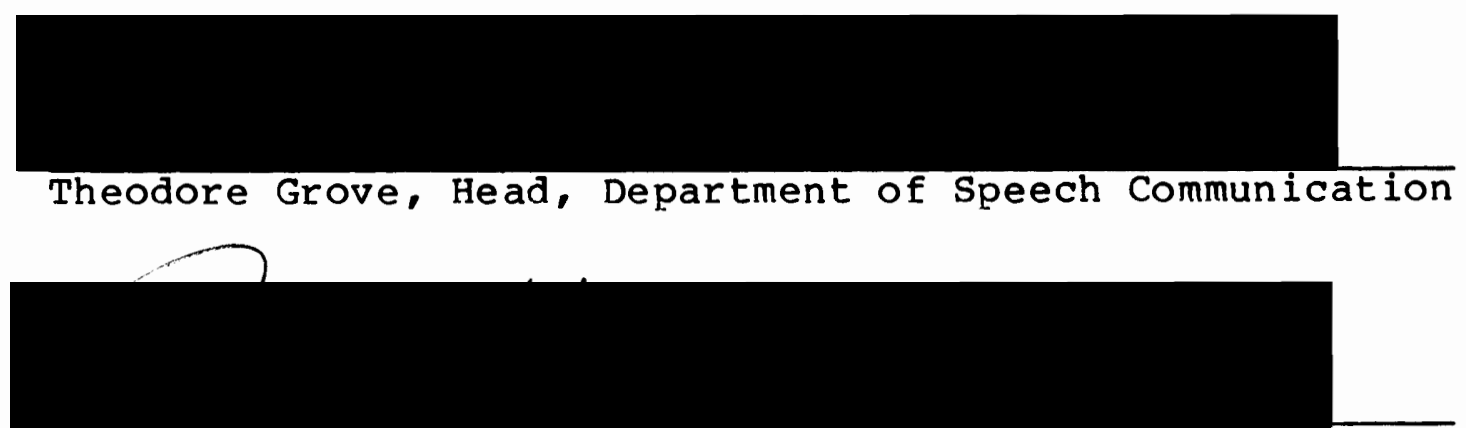

Jjm F.l Heath, Dean of Graduate Studies and Research 


\section{ACKNOWLEDGEMENTS}

I wish to thank my creative advisor, Dr. Bennett, and the other members of my committee, Dr. Kosokoff and Dr. Barna, for their obvious interest and focused attention. The benefits were great. In addition, I wish to express my appreciation to Dr. Manson, whose wellness background within Alaskan Native communities provided important direction.

I would also like to thank my son, Timo Christopher Allan, whose moral support and sense of humor kept me smiling. And special thanks go to my friends who, because of their humanistic and nuturing ways, helped me to complete this study without a major stress-related disorder.

But most of all I wish to express my appreciation to the members of the Native communities of sitka and outlying villages. Their personal accounts of Native transitions gave me insights into the broader meanings of such terms as "forgiveness," "health," "my people," and "alcohol recovery." Their commitment to the mental, emotional, and physical health of their people was a constant inspiration to me during the field research and thesis writing.

This study is truly a "holistic" endeavor. It was conceived with physical health in mind and developed with an enormous amount of mental and emotional energy. And, for me, it resulted in a new understanding of the word "spirit." 
TABLE OF CONTENTS

PAGE

ACKNOWLEDGEMENTS. . . . . . . . . . . . iii CHAPTER

I INTRODUCTION. . . . . . . . . . . . 1

Rationale .. . . . . . . . . 1

Major and General Research Questions . . 8

Format of study . . . . . . . . . . 9

II THEORETICAL BACKGROUND. . . . . . . . . 11

The Anthropological Perspective on Cultural Values ........... . 11

The Intercultural Perspective for Communication .......... . 18

Wellness and Health Promotion Concepts and Definitions . . . . . . . . 25

Health and Wellness within Native Culture . . . . . . . . . . 29

Health Locus of Control Concept . . . 38 III METHODOLOGY . . . . . . . . . . . 45

Statement of Design ... . . . . . 45

Purpose

Overview

General Methods . . . . . . . . 47

Instruments . . . . . . . . . 50

Interview Schedule of Questions

Health Locus of Control Scale Questions validation 
Population. • . . . . . . . . •

Subject Selection

Procedures •. . . . . . . . . . 57

Data Analysis . . . . . . . . . 58

IV RESULTS AND DISCUSSION . . . . . . . . 60

Transitional Life-styles . . . . . 60

Native Health and Wellness Indices . . 64

What non-Native Health Professionals Should

Know About Natives and their Culture . . 69

Communication-based Responses

Culture-based Responses

Health/Wellness Counseling . . . . . 78

Data Related to "Relationshio to Health"

value . . . . . . . . . . . 80

Interview Responses

Health Locus of Control Responses

t-testing of HLC Data

Data Validation . . . . . . . . . 90

Summary • • • • • . . . . • • • 92

V APPLICATIONS OF THE INTERCULTURAL PERSPECTIVE TO PROBLEMS IN INTERCULTURAL COMMUNICATION AS REPORTED BY NATIVES • • • • • • • • • • • • 94

Intercultural Training for Health

Professionals . . . . . . . . . 99

VI SUGGESTIONS FOR FUTURE RESEARCH • • • • • . 102 BIBLIOGRAPHY • . • . . . . . . . . . . . 107 APPENDICES • . . . . . . . . . . . . . . . . 112 


\section{CHAPTER I}

\section{INTRODUCTION}

\section{Rationale}

A small but important American population appears to be suffering from a combination of ethnocentrism and the diseases of civilization. This population, the Alaskan Native, has endured and survived the devastating effects of infectious disease epidemics subsequent to contact with "the white man." And today these same people are facing an assault on their health that is more subtle and chronic but equally devastating. The negative side effects of all-too-rapid acculturation into the western world must be addressed to ensure continued survival.

It appears that the same ethnocentric attitudes that in the past made Native foods, language, life-style, social customs, and world views unacceptable to nonNatives continue to be held. This ethnocentrism may be a major obstacle to good communication within health-care systems provided for Natives.

The health care organizations are attempting to confront the negative side effects of rapid adaptation into American culture. But such diseases of civilization as 
alcohol abuse and its multivariate illnesses, family dissolution, diabetes, hyptertension, obesity, and other chronic health problems continue to plague Native people and defy conventional medical treatment.

This study looks at current approaches to health care--both curative and preventive--with a focus on the communication of wellness concepts. Specifically, it will focus on the wellness counseling interactions between Native clients and non-Native health professionals. It takes an in-depth look at ethnocentrism and diseases of civilization with the end goal of improving communication of essential self-help skills for Natives in today's technological world.

Acculturation into western medical ways is now a fact of life for all Alaskan Natives. The tuberculosis epidemic finally attracted the attention of the federal government, so that by the 1950's the Public Health Service undertook primary treatment of the disease at $M t$. Edgecumbe Hospital, Sitka, Alaska. Here new chemotherapy and corrective surgical procedures were instituted with dramatic success.

As a long-time employee of the Indian Health Service/Public Health Service who worked in conjunction with the Southeast Alaska Regional Health Corporation (a nonprofit Native corporation which continues to assume greater responsibility for Native health care), I began 
to examine the meaning of "culturally relevant" health care, the term employed to describe health care that fits the values and life-styles of the people it serves.

There is a growing awareness within both Native and non-Native Alaskan health groups that major value differences continue to exist between Native clients and nonNative health professionals. And there exists much rhetoric regarding the importance of "culturally-relevant" health care. Employed to educate both Natives and nonNatives regarding disease prevention and promotion of healthy life-styles, I developed and implemented health and wellness promotion programs in both small Native villages and towns. I personally confronted some of the Native/non-Native value differences important to the communication of these health concepts.

Unlike acute and emergency health care, which depends on skills of the health professional, preventionbased health care depends on the client's information, personal motivation, and the necessary skills to implement a desired health-behavior change. The focus is on selfresponsibility and involvement of the client, not the information held by the health professional. Health promotion activities concentrate on the communication of facts, increasing motivation and enthusiasm for change, and providing skills to implement the desired behavior change. 
Because infectious disease has peaked and the major health problems of Native people are life-style-related, Alaskan Native health corporations as well as the Indian Health Service have adopted prevention concepts and wellness approaches as bases for much of their health care philosophy. And, since ". . the leading causes of morbidity and mortality in Alaska are behaviorally based, prevention is closely related to modifying behavior and changing social conditions" (American Public Health Association, 1981 , p. 12).

Alcohol abuse and its associated illness, accidents, and family disruption, as well as other "diseases of civilization" such as heart disease, hypertension, and diabetes are the epidemics that face Native people today. Just as chemotherapy brought a means of survival during the tuberculosis epidemic of the 1950's, so preventive health care may potentially provide survival tools necessary for the management of this current epidemic.

My experience with the communication of health and wellness concepts led me to question the cultural relevancy of most currently available health and wellness education materials. Frequently films and other materials would focus on life-styles and values of mainstream Americans who lived in major urban areas. When health education personnel were viewing films and other media materials for "cultural relevancy," the obvious life-style 
factors such as the kinds of occupations, cars used, clothes worn, locations etc. were evaluated. Racial heritage of role models was also considered. For example, could an Indian child identify with blonde, blue-eyed children in a film?

But more subtle than visual appearances of those representing health and wellness in films, was the ascertaining of underlying values that motivated the film. For instance, McClure (1982) notes that mainstream American values emphasize a preoccupation with youthfulness, sexuality, and longevity. She states,

In our society this concept of 'lookin' good'-being tall, slender, blue-eyed-blonde--excludes people of color: so it is even more important to include in our concept of 'lookin'good' the emotional, spiritual, and intellectual definition of wellness in a health care model (p. 26).

This applies to health media materials as well. For example, in contrast to the mainstream American emphasis on youthfulness and longevity, Natives have traditionally looked to their elders as role models who contribute answers to life's challenges. And today, although they pursue educational opportunities for their young and value these youthful resources, many Natives look forward to becoming older, and do not seem to fear the aging process. It seemed possible that this difference in the value orientation of "age versus youth" might be just one example of value differences that might influence the communication of wellness concepts. For example, losing 
weight to achieve a youthful appearance might not be the motivating factor for a Native client that it is for a non-Native.

And so it became incumbent upon us to search for media and other wellness material that more satisfactorily reflected values and beliefs of Native people. However, we were unaware of how major a task we had undertaken.

My study is an outgrowth of this desire to understand Native clients' values and beliefs, in the hopes of developing wellness and health promotion programming and counseling approaches that are appropriate. The acculturation process for Natives in southeast Alaska has had profound effects on thinking and behavior, but how great an effect? In a 1980 health document prepared by the Alaska Native Health Board, DeGross stated that "Western colonial practices assaulted not only the immune system of Alaskan Natives, but also their wildlife and food resources, social and family organization, religious and medical belief system, and traditional health practices" (p. 4). Different cultures represent a wide variety of values and beliefs regarding health and health promotion. These values and beliefs about health evolve over generations, changing and adapting to discoveries within their own culture and discoveries made by contacting other cultures. Values and beliefs that underlie health behaviors 
are as much a part of a culture as their religious or social systems.

The Alaskan Native is no exception to this pattern.

For thousands of years the aboriginal peoples' of Alaska-Tlingit-Haida, Athapaskan, Inupiat and Aleut--held a complex set of beliefs regarding the nature of health and disease, the power of health "common sense" within their own group, and the methods such as herbal medicines and shamanism used by the trained members of their group (Lantis, 1963).

\section{Summary}

It became clear to me and other health educators that although acculturation of Alaska Native people into the western medical system is a fact of life, culturally relevant health care would only be possible when health care programs fit the values and belief systems of the clients. And this would be possible only if face-to-face communication between Native clients and their non-Native health professionals resulted in a mutual exchange of information.

Without information regarding values, beliefs and attitudes of Native clients, there would continue to be one-way communication; that is, medical information would be directed at the Native client without regard to Native feedback and processing of the information into meaningful 
action. This study focuses on the intercultural communication process that occurs between members of one Alaskan Native group, the Tlingit-Haida Indians, and their nonNative health professionals.

The following section clarifies the major and general research questions which this study addresses.

\section{Major and General Research Questions}

This study seeks to answer certain questions that are central to the major research question of:

To what extent do Native and non-Native cultural values differ and how might these differences affect the communication of health wellness between Native clients and non-Native health professionals?

The specific underlying cultural value on which this study focuses is that of "Man's relationship to his health" and the specific Native population to which it refers is that of southeast Alaska Natives.

This study provides a vehicle by which this major research question may be answered. The following general research questions were utilized in order to obtain data necessary to answer the major research question:

1) How has the transition from traditional to modern ife-styles affected Native values; 2) How do Natives and non-Natives differ in their perceptions regarding who or what controls a person's health; and 3) What should 
non-Native health professionals know about Native clients and their culture that would assist them in becoming more effective health counselors.

Employing both the oral interview and written survey methods of data collection, responses to the above questions are analyzed in Chapter IV, Results and Discussion. The responses are evaluated in light of anthropological concepts of cultural values, the intercultural perspective of communication theory, health and wellness concepts, and literature concerning the health effects of modernization on Native culture. This theoretical background provides a framework for understanding the variables affecting the communication of wellness within this intercultural context.

\section{Format}

The format for this thesis is as follows:

Chapter I presents an introduction to the thesis which includes the rationale for the study, the major and general research questions, and this detailed format.

Chapter II presents the theoretical background necessary for an understanding of the issues addressed by the study. This background addresses: anthropology-based theory of cultural values; the intercultural perspective for communication; wellness and health promotion concepts and definitions; health and wellness within Native culture; and, the concept of health locus of control. 
Chapter III presents the descriptive methodology including the methodological techniques of oral interview and written instrument. The design of the study, including the purpose, data collection, and methods of analysis is also discussed.

Chapter IV presents the study's results and discussion, relating results to theoretical concerns mentioned in Chapter II. The data relates to the general research questions regarding transitional Native life-styles, health and wellness indices for Natives, the question of who or what is in control of a Natives' health, data concerning what non-Native health professionals should know about Natives and their culture, and a data validation discussion.

Chapter $\mathrm{V}$ addresses the applications of the intercultural perspective to communication problems as reported by Native interviewees. This chapter will provide potential solutions for the reported communication problems, utilizing the face-to-face interactive, difference-based, processual, and humanistic approaches. It also includes a brief discussion regarding intercultural perspective-based education for health professionals.

Chapter VI includes directions for change and ideas for future research. 
CHAPTER II

THEORETICAL BACKGROUND

The Anthropological Perspective on Cultural Values

The following is a brief overview of some theoretical value concepts useful in the understanding of Native and non-Native perceptual differences. The discussion will be divided into two parts. First, an overview of value concepts will be presented. And second, an overview of mainstream American value-orientations as they contrast with traditional Native culture will be provided.

\section{Value Concepts}

Cultural values are complex, most often unconscious, and difficult for researchers to identify. Kluckhohn (1951) has said ". . about the only defining point about $v a l$ ues which is qenerally agreed upon is that they have to do with normative as opposed to existential propositions" (p. 393). In other words, values point to what is bad or good, right or wrong. Kluckhohn and Strodtbeck (1961) have referred to the element of "oughtness," the prescription of values for the individual regarding what he or she ought to do in a certain situation. 
And, Stewart (1972) discusses more specifically American cultural norms, value prescriptions that are ". . explicit and repeatedly involked by Americans to describe or justify their actions." He describes the concept of self-reliance as an emotion-packed "ought" that affects actions of Americans but does not $n$. . provide a systematic explanation of the behavior." As Stewart also notes, cultural norms such as self-reliance give a contextual framework for value systems but don't explain contradictory behavior (p. 19).

Ethel Albert's (1968) definition of "value system" is important in that it gives an explanation of why our behavior often does not exemplify our values. She notes, "A value system, then, represents what is expected or hoped for, required or forbidden. It is not a report of actual conduct but is the system of criteria by which conduct is judged and sanctions applied" (p. 288). We are most frequently unaware of the "why" behind our behaviors. Consequently it is difficult to ascertain these values.

The goal of this study is to uncover and explore Native cultural values that pertain to health-related behaviors. In particular, this study focuses on Rluckhohn and Strodtbeck's (1961) value orientation of "Man's Relationship to Nature" with the "nature" extended to mean human health. This value orientation scheme has assisted 
the writer in categorizing the values uncovered in the study.

Although Rluckhohn and Strodtbeck divide values into categories, (for instance, "Man's Relationship to Nature"), they are aware that any system arbitrarily divides up parts in order to better understand them. These value "parts" that will be discussed here often overlap and influence one another (p. 4).

Hall (1977) seems to agree when he notes:

- - in spite of many differences in detail anthropologists do agree.. . there are characteristics of culture: it is not innate, but learned; the various facets of culture are interrelated-you touch one culture in one place and everything else is affected; it is shared and in effect defines the boundaries of the different groups (p. 16).

Value orientations look at the many options a culture has for solving a limited number of common human problems, such as how humans relate to nature or others. There appears to be a limited number of solutions to these common human problems and all solutions are present in any one culture. However, there is a primary or dominant solution usually present, existing as the normative value for the majority of members of the culture (Rluckhohn and Strodtbeck, p. 4).

It should be noted that in order to discuss differences between cultures, generalizations will be used; "generalizations" meaning the normative or majority value 
orientation of the culture. It is recognized that deviation from this normative standard will occur in all cultures. As Kluckhohn and strodtbeck note,

Our most basic assumption is that there is a systematic variation in the realm of cultural phenomena which is both as definite and as essential as the demonstrated systematic variation in physical and biological phenomena" (p. 3).

However, in finding contrasting examples from other societies we shall turn to the dominant regularities.

stereotyping, in contrast to generalizing, does not allow for cultural variations or deviations. As Brislin (1981) notes, ". - . stereotypes refer to any categorization of individual elements concerned with people which mask differences among those elements" (p. 44). This study will employ generalizations in order to point out differences between normative values of mainstream American and Native cultures.

Major Contrasts Between Mainstream American and Native Cultural Values

The second part of this discussion deals with normative value contrasts between American and Native cultures. The traditional values fit what Stewart (1972) calls "gemeinschaft," non-western cultures that are usually rural and traditional. The characeristics common to these traditional cultures have been true for traditional Native culture (Stewart, p. 10). 
One major characteristic of a traditional culture is that members define themselves in terms of social links. Native culture traditionally stressed the clan and group relationships. A complex society, the Tlingits had a highly developed kinship system consisting of what anthropologists called "moities." Moities divided the culture into two major groups, the "Eagles" and "Ravens" (Lantis, 1963, p. 4). In addition, "Social units, built up along matrilineal lines, had their own houses and chiefs, their own crests and personal names, and their own ceremonial songs and dances" (U.S. Dept. of Interior, 1985, p. 1-12). The relationships between members of these well-defined groups were respected and maintained through ritual behaviors, class distinctions, and leadership expectations. These important kinship relationships provided the basis for a strong group orientation of Native peoples that contrasted with the mainstream American "individualism" orientation. Although Americans have always been strongly motivated by the value on the individual, ". . it does not mean that they do not show some affiliative tendencies. These tendencies, however, are diluted in contrast to the strong social and territorial adhesion found in affiliations in the non-western world" (Stewart, 1972, p. 43). 
One other cultural value that markedly differs between mainstream American and traditional Native culture is that of the orientation of "Man's Relationship to Nature." The dominant orientaton in American culture is that of control of the physical world in the service of man. As stewart notes, "The natural laws assumed to underlie the physical world seem to be harnessed for producing material welfare and hence are at the service of man" (p. 62).

This contrasts greatly with the traditional Native subsistence ethic. Within the subsistence ethic lies the assumption that the Native lives and survives within nature and that the Spirit world and the natural world are linked. Traditionally, the Native hunted, fished, and utilized the natural resources to the extent necessary for survival, not profit. During the background interviews with elders, examples were given frequently of how grandfathers and uncles espoused the harmony-with-nature ethic. For instance, I was told by one elder that he was beaten when his uncle learned that he had caught more fish than he needed for that day's meal. One was never to catch more than necessary. And frequently mentioned was a thankful communication with an animal before it was killed.

A third cultural value orientation that clarifies a difference between mainstream American cultural and tradi- 
tional Native culture is that of "Age versus Youth." As Condon and Yousef (1980) note, "A youth-valuing culture (including the United States) values--along with some degree of maturity--vigor, idealism, and a freshness that is thought to be dissipated with age" (p. 69). "Experiences" are preferable to "experience." Technological advances are often fostered by youthful scientists looking to the future for answers to mankind's problems.

This contrasts greatly with an orientation which values age and experience. As Condon and Yousef (1980) note, "The value of age has traditionally been the dominant orientation of most cultures in the world, for the elders of societies were the repositories of knowledge as well as the locus of power and authority" (p. 69). Traditional Native culture looked to elders for answers to their problems; elders were the "culture-bearers" and it was from them that young people learned the myths, the history, and the wisdom of their culture.

During background interviews with elders I heard many descriptions of young people sitting around an elder uncle listening to stories of Raven and his many exploits. Many hours of a child's day were spent listening to the recounting of mythological and historical events important to their culture. Elders were viewed as important resources and were treated with great respect. 
In summary, traditional values often contrasted with western/American values. When aboriginal Natives first contacted the "white man" the differences between their value orientations were probably nothing more than phenomena to be negatively evaluated, but as the two groups were forced into closer and closer proximity, these differences became problematic.

As Natives adapted increasingly to the "white man's" life-style, cultural values as well began to change. The following section addresses the intercultural perspective for communication, an approach to communication that may clarify how cultural value differences may result in communication problems and also provide possible solutions.

\section{The Intercultural Perspective}

The following is an overview of the intercultural perspective for communication. According to Bennett $(1984)$, the intercultural perspective of communication theory is defined as: 1) Difference-based, 2) Face-toface interactive, 3) Processual, and, 4) Humanistic. This perspective gives the individual a perceptual tool for confronting the anxiety that results from transition and change, conflict, ambiguity, and new information which are integral parts of communication between people of different cultural world views. 
In general, this perspective, or way of viewing communication, shifts the focus away from one's own world view--that which the home culture teaches are "facts" and "realities"--toward the creation of another mutually agreed upon meaning. This shared meaning is constantly changing, in process, and is not dependent upon one or the other's absolutist views regarding reality.

The following discussion concerns the four components of the intercultural perspective. Viewed as a perceptual tool, this difference-based, face-to-face interactive, processual, and humanistic approach to dyadic communication allows the dyadic participants to be selfreflective and, consequently, to act rather than merely react to new experiences. This proactive participation in the communication experience allows a freedom to create and recreate common meaning.

The first component of the perspective, the "difference-based" factor, the writer considers to be the central concept on which the others depend. As Bennett notes,

- . the reality which we experience is constructed according to variable cultural patterns, and . . - these differences are the crucial factors in our attempts to understand the communication experience" (p. 5).

And Hoopes (1981) confirms the importance of cultural differences when he notes, 
Al though individuals attempt to protect themselves against wide differences in ways of expression and perception, . . differences exist and are a cause of static (p. 33 ).

And, as Hoopes also notes, although these cultural differences are inherent and natural they are also most often out of our awareness. Hoopes' research subject, that of cross-cultural education, concerns the development of skills to cope with these out-of-awareness differences in world views and value systems that are reflected in communication. Cultural awareness allows for dyadic members to deal with the "static" he describes. Static refers to communication in which complex numbers of distracting variables exist, as in intercultural communication, but does not imply that there is something wrong with the communication. It is, rather, very complex and requiring a greater degree of cultural awareness than communication with those of common experience (p. 33).

In contrast to difference-based approaches, there is more often a diligent search for commonalities, a desire to believe that "deep down inside we're all alike;" as Barna (1982) notes,

The aura of similarity is a serious stumbling block to successful intercultural communication. - . The confidence that goes with the myth of similarity is much more comfortable than the assumption of differences, the latter requiring tentative assumptions and behaviors and a willingness to accept the anxiety of 'not knowing' (323). 
Bennett agrees and discusses the "minimization of difference," a focus on similarity for the purpose of decreasing the anxiety that results from ambiguity, which ". . may help maintain a fairly comfortable state of ethnocentrism" (p. 27).

The ramifications of difference-based institutions are many. One possible result is that of the creation of pluralistic rather than monistic-based organizations. This pluralistic attitude opposes the melting-pot ideal and advocates instead a society where toierated, skin color is not a criterion of
mobility, many different ideas can be freely
expressed, and a wide range of behaviors are seen
as appropriate in meeting everyday needs interpersonal relations" (Brislin, p. 288).

In addition to the difference-based focus, the intercultural perspective is also face-to-face interactive. It emphasizes the face-to-face interactions between two culturally-different persons. This contrasts with a cultural investigation of the differences between different cultural groups. It focuses on the specific dyad whereas cross-cultural investigations focus on the general society and general normative behaviors for members of a certain group.

The intercultural perspective asks the question "What happens when two specific individuals, representing diverse cultures, get together for face-to-face inter- 
actions?" Hoopes (1981) partially answers this question when he notes that "cultural codes," all the cues and behaviors involved in communication, are a complex interaction of behaviors. And, ". . the cultural code is all--with the exception of language--that in the nexus of human interaction has meaning." Asserting that "behavior communicates," he notes that verbal or silent, smiling or non-expressive, communication behaviors have a profound effect on an interaction (p. 29).

The third component of the intercultural perspective, that of processual rather than linear approaches to the "creation of meaning," focuses attention on mutuallyderived meaning, rather than the message itself. In the conventional view of communication the emphasis is often on the sender or the message, encouraging an attempt to either clarify the structure of the message itself or improve the communication style of the sender. The importance of these activities are not denied but the major focus of the intercultural perspective is on what occurs between the dyadic participants that is unique to them. The processual view, in contrast to a sender or message focus, asserts ". . even more important is the feedback process, the response of the listener to the person sending the message" (Hoopes, p. 39). Hoopes also states that effectiveness of communication is dependent on ". . the degree that it is a two-way process in which 
successive approximations of accuracy in getting meanings across are achieved" (p. 39).

However, attempts to increase communication accuracy are fraught with difficulty. And Bennett (1984) suggests that for effective communication there must be self-reflexiveness, an understanding that $n$. . in terms of human behavior, .. there exists, for man, only subjective reality, i.e., the universe as individual men perceive it" (p. 41). And, as singer (1982) notes, the individuals involved must share the belief that ". . the 'same' stimuli are often perceived differently by different individuals and groups" (p. 54).

Combining Hoopes' "cultural codes" and singer's ethnorelative beliefs about reality, Bennett moves to the ". . willingness to give up 'temporarily' one's own world view in order to experience another" (p. 41). This "shift in frames of reference" constitutes a phenomenon central to the processual aspect of the intercultural perspective. Bennett's concept of empathy necessitates such a mental shift, practicing ". . the imaginative participation in a different world view ..." (p. 41).

In addition to the circular, ever-changing process of creating meaning, the intercultural perspective requires that communication be humanistic. In contrast to a positivist view of reality, where absolute truths exist, humanistic approaches accept multivariate realities. 
In the area of modern medicine this aspect is vital, although not often recognized. Western medicine has developed technologies that few can disregard. However, with its scientific approach, the systematic division of the mind/body into small parts for the purposes of study, there is a positivist attitude that prevails. Westerntrained medical personnel frequently reflect this belief by their acceptance of ultimate answers that science seems to qrant us, often disregarding as "folk tales" many other forms of healing that exist today.

A humanistic approach to healing would assert that the healing method, whether it be medication, surgery, a health/wellness activity, or shaman ritual, is merely a tool and that the focus and the major ingredient for healing is the whole individual. Currently, medical practice generally focuses on new technologies rather than the individual's complex and intricate process of healing.

In summary, communication researchers Hoopes (1981), Bennett (1984), Barna (1982), Singer (1982), and Brislin (1981) emphasize various aspects of the intercultural approach to communication. This perspective is face-to-face interactive rather than cross-cultural in focus, difference rather than similarity-based, processual rather than linear, and humanistic rather than authoritarian. There is significant theoretical basis for this perspective and good reason to postulate its important appli- 
cations for improvement of dyadic communication between persons of different world views; and specifically, to the dyadic communication between non-Native health professionals and their Native clients.

\section{Wellness and Health Promotion Concepts and Definitions}

The following discussion will address the concept of wellness and the definitions necessary to the understanding of health care based on this concept. This discussion will be followed by an overview of wellness and health promotion as they are manifested in southeast Alaska Native culture.

Because the western medical tradition has focused primarily on the ameliorative, or curative, approach to health, the English language is rich in the language of pathology and disease. Few words are descriptive of health maintenance, wholeness of "body-mind-spirit," or a high level of health (Manson, Tatum, and Dinges, 1982, p. 15).

These researchers note,

Health is usually conceptualized as one endpoint on a continuum of disease presence or absence. Alternative perspectives attempt to circumvent this dichotomy by emphasizing the maximization of personal potential. Growth, wholeness and competence are frequently used to describe the ensuing phenomenon of interest. This limited vocabulary which is available for discussing health in this latter sense stands in marked contrast to the richly varied vocabulary that characterizes the subject of disease (p. 15). 
"Wellness" is a word created within the last ten years for the purpose of expressing these health-enhancing concepts of health maintenance and promotion. For the purposes of this study, wellness is operationally defined as ". - an enhanced dimension of health and involving good physical self-care, using one's mind constructively, and expressing one's emotions effectively. . ." (Carroll, 1982, p. 2).

Other definitions important to the understanding of the wellness approach to health are:

1. Health-- ". . not just the absence of disease or comfort, but a process of continuous adaptation to the many microbes, irritants, pressures and problems which daily challenge humans" (Carroll, p. 2).

2. Primary Prevention-- ". . an approach which seeks to lower the prevelance of disease by reducing its incidence. . " (Manson et al. 1982, p. 12).

3. Health Promotion-- ". . health promotion and enhancement involve skills, and building or augmenting adaptive strengths, coping resources, survival skills, and general health (Manson et al. p. 46).

4. Stress Reduction--the ability of the individual and/or group to decrease the negative health effects of stress; and defined as ". . - the non-specific response of the body to any demand upon it" (Seyle, 1974, p. 14).

5. Holistic Health--An approach to health promotion that incorporates the total person, including the body, mind, and spirit.

6. Life-style--The physical, psychological, social, economic, emotional, and spiritual behaviors practiced regularly by an individual.

7. Diseases of civilization-- Those chronic and debilitating diseases which result from the 
cumulative effects of a life-style of poor nutrition, sedentary behaviors and an inability to manage the negative effects of stress.

In order to understand the wellness approach to health it is important to recognize that central to health promotion and enhancement activities is the ability of the individual and/or group to deal effectively with conditions which are stress-causing. The life-style which promotes a high level of nutrition, regular activity level, and ways in which to successfully deal with emotions is a life-style which improves the general health of a people. The individual and/or group that takes responsibility for these basic health-promoting activities will increase physical and mental adaptive strengths, stressreducing resources, and survival skills that play a major role in health promotion.

McClure (1982) notes the need for health professionals to understand the integrative nature of wellness-based health care when she states:

In applying this holistic concept of health to people of color. . . it is essential for health care providers to assume the 'wellness 'of their cultures, as well as the 'wellness' of their race. It is essential to assume the 'wholeness' of their cultural blueprint for living, the internal consistency of their cultures, in order to balance effectively scientific/technical expertise with the spiritual/emotional variables considered important in maintenance of wellness in the cultures of people of color (p. 23).

In support of this view, Manson et al. assert that within Native communities exist examples of health competencies. They state that concentration on 
psychological and physical pathology can be replaced with ". a more positive view of the potential for... maturity and competence both individually and collectively. . " (p. 47).

However, in order to understand the potential for physical and mental competencies within Native culture, it is critical to acknowledge the physical and mental stressors that have historically confronted Natives and those which they currently confront.

As noted earlier, during the last 25 years since their dramatic recovery from tuberculosis, the Alaskan Natives have struggled with yet another devastating epidemic--that of alcohol abuse and the other life-stylerelated illnesses. Unfortunately, because these health problems have their bases in health behaviors and 1 ifestyle choices rather than in external causes such as pathogenic bacteria, scientific medical advances are frequently ineffectual as cures. It seems that disease and illness linked to life-style patterns often defy scientifically-based medical treatment.

As Fortuine (1975) notes, this category of disease may be called "diseases of transition"--disorders which have resulted from cultural change or the introduction of new modes of living, housing, food habits or transportation" (p. 6). Besides alcohol abuse and rampant dental decay, ". - no doubt largely attributable to the wide- 
spread and indiscriminate use of highly refined sugars in the diet," (p. 6) other chronic and debilitating diseases such as hyptertension, diabetes mellitus, duodenal ulcers and some types of cancers are on the increase. In addition, anxiety, depression and suicide currently plague Native communities.

The following discussion gives an overview of how wellness and health promotion are basic to southeast Alaska Native culture.

Health and Wellness Within the Native Culture

Traditional Health and Wellness Practices

It is important to note that there were health practices and traditions among the aboriginal southeast Alaska Natives that seemed to ease them into the modern medical care systems; and that traditional Native life-style behaviors existed that protected and hardened the body and mind against much mental and physical disease and illness (Lantis, 1963, p. 6).

As Lantis notes,

- Alaskans of southeast Indian descent are not a people indifferent to disease. They do not take it for granted, as do so many races of fatalistic tradition. . (p. 6$)$.

This Native group held health beliefs that paralleled some of the western practices to which they adapted when contact with Western medicine was made. Four major traditional theories of disease are important to understand. 
First, there was accepted the theory of some object being introduced into the body by an evil spirit or enemy. It was the shaman's responsibility to remove the "intruding evil." Through elaborate performances of dance, song, and chants, the shaman was often successful in removing the offending object. In modern medicine it is the physician-surgeon who is responsible for removing the offending or diseased part of the physical body (Lantis, p. 7).

Another explanation of illness was that of "losind one's soul." with the assistance of a spirit helper, the shaman was responsible for locating the soul. Once again there seems to be a western medical parallel. Psychologists, in a sense, assist the client in finding the "self" or soul. In both cases, "the spirit is renewed" (Lantis, p. 3).

In addition, rituals of cleansing and self-purification were implemented by hunters and warriors to increase strength. And fish camps were kept scrupulously clean to ward off disease. Consequently, the missionaries' emphasis on "cleanliness is next to Godliness" was not a foreign concept.

Finally, contagion magic was important. This basic belief asserted that body parts such as nail clippings and excrement held certain power. If the enemy were to burn body parings, the owner would also be burned or the enemy 
would otherwise put a spell on the owner. Consequently body parings and waste of all kinds were scrupulously disposed of. This black and white contagion magic concept paralleled the theory of pathogenic bacteria in that it required that body excrement and discharges must be discarded.

In addition to these methods of treatment and prevention of disease, herbal remedies were abundant. McGregor (1981) states that ". . many herbal and dietary remedies were a part of the 'common sense' or common knowledge of the community and were passed from parent to children" (p. 65). Having utilized the medicinal powers of herbs for thousands of years, the transition to modern forms of medication was not difficult.

In combination, the concepts of cause and effect, contagion causes of disease, cleansing rituals, and herbal medicines for prevention and treatment of illness, together formed a health-care framework that allowed for a relatively easy transition into the western world of medicine (Lantis, 1963, p. 7).

As the above description of traditional practices indicates, southeast Alaska Natives had developed a complex system for the treatment for mental and physical disease. In addition, however, traditional health practices included a physical and mental life-style that promoted health and prevented disease. 
For example, the Southeast Alaska Regional Health Corporation (SEARHC), has published a pamphlet (1984) describing traditional strengths:

Long ago, our ancestors knew what it meant to be a real person--a Tlingit. They knew that to survive in the world they had to be strong both in body and in their soirit.. . What made our people strong? They ate good food, they trained their bodies, but more than that, they had strong minds (p. 1).

These strengths were drawn from cultural values focused on clan and kinship relationships and the subsistence way of life. Subsistence, defined as the minimum food or shelter to support life, means much more to the Native people.

Tlingit people have learned how to survive the weather and keep body and soul together. We have special regard for the fish and other animals we use for food. We know and respect the weather and the waters. Fish streams, hunting grounds, and berry patches were more than a means of filling our 'minimum daily requirements'. For us subsistence food is a tangible link with the past, with a way of 1 ife that is quickly fading (U.S. Forest Service, 1984, p.iii).

The subsistence life-style incorporated physical activities such as hunting, fishing, berry picking, boat rowing, hauling of water. In addition, this life-style required mental and spiritual health in order to maintain a consisent motivation to work year-round at these many maintenance tasks. As the 1985 Alaska Native Claims Settlement Act Study states regarding Alaska Natives, 
In adapting to their varied environments, all adopted a subsistence way of living; they obtained food, clothing, and shelter from the land's resources at all times of the year (U.S. Dept. of Interior, p. 1-12).

And this study also notes that for the Tlingit-Haida tribes specifically:

- - The richness of resources meant that a surplus could be acquired, and thus the Tlingit's and Haida's cultures emphasized the amassing of wealth. . Great quantitites of food and gifts were collected for potlatches. . ( $p .1-12)$.

In addition, the cultural emphasis on clan and

family relationships was also central to mental and physical strength of traditional people.

They worked hard and trained the young people what it meant to be Tlingit. At times they were told stories about people who had become great through hard work and determination. Many of the stories were lessons for the mind. Everyone was Tlingit-a real person--but everyone was also a member of a family. Some people were named after famous ancestors - . - Whatever they did, or did not do, would bring shame or pride to their family. No one stood alone (Southeast Alaska Regional Health Corporation, p. 2).

And finally, individuals within the culture experienced rituals that promoted mental and physical well-being and decreased the incidence of stress-related conditions. An important example is that of the memorial potlatch. As

Kan (1983) notes, this was a complex ceremony.

- . I see the rhetorical utterances made in the Tlingit memorial potlatch as elocutionary acts aimed at transforming the experiences of the participants, strengthening their social ties, raising their status, and restoring the balance in their social universe and cosmos (p. 48). 
This description is remarkably similar to that of alcoholism recovery. Alcoholism recovery is also described as a process of increasing self-esteem, strengthening social ties, increasing status in community, and restoring the mental, physical, and spiritual balance of the victim's lives.

In combination, supportive clan and kinship relationships, the subsistence life-style, and mental and physical health-promoting ceremonies provided a social setting that fostered positive health behaviors.

Acculturation and Its Effects on Today's Native Health

The above-noted traditional health practices and life-styles seemed to provide Natives with mental and physical strengths needed to deal with disease and illness endemic to them. But these practices suffered greatly under the stresses of adaptation into the western world. As Segal (1983) notes,

Not unrelated to the current stress placed on the traditional life-styles of the Alaska Native is development of the state's natural resources, particularly oil. . . As a result, the Alaska Native Claims Settlement Act, which passed Congress in 1971, conveyed to the Natives 44 million acres--changed from aboriginal title to fee simple title--and compensated the Natives nearly a billion dollars. . . . The act initiated a series of changes which have been described as a movement 'from tribalism to corporations'. . . and the survival of the Native people is directly contingent on the success of the regional corporations (D. 383). 
As Segal also notes, this new kind of challenge facing contemporary Natives, these new stressors, are not well understood. He notes,
- - Alaska Natives have been subject to inordi- nate amounts of stress, a significant amount of which can be directly attributed to the problems and difficulties involved in the introduction of the Western world with all its attitudes, reli- gions and technology" (p. 383).

This movement from subsistence life-style to the cash and corporate economy appears to be a major challenge confronting Native survival.

Segal, in his search for important research questions regarding Natives and alcohol abuse, asks: "How have the strain and stresses of emotional conflict which are 1 inked to the intensification of the acculturation process, affected the life-style, value system, and behaviors of the Alaskan Native people? What is the perceived role of alcohol in this process?" Although this study does not address this question specifically, an overview of the acculturation history and health status of Natives reveals a link between the two factors.

In order to better understand this link between rapid adaptation into the modern world and Native health status, it is important to understand that rapid adaptation was not merely thrust upon the Native peoples of southeast Alaska. That although the arrival of Russians and other Europeans around the middle of the eighteenth century necessitated major forces influencing Native 
life, for the Tlingits, at least, there existed an element of choice as to the degree of acculturation attempted.

In 1919 Native leaders founded the Al aska Native Brotherhood, an organization whose goal it was "... to encourage a Christian morality among the Indians of Southeast Alaska and to campaign for full citizenship for their people" (Preamble A.N.B. Constitution, 1980, p. 1). The founders, whose parents and grandparents spoke only Tlingit and iived the traditional subsistence life-style, were the first graduates of the Sitka Training School, a Presbyterian-sponsored school. The young founders were encouraged by their elders to lead their people into the white world. They saw no other way to deal with what appeared to be an unending influx of whites into their traditional lands.

The following are excerpts from the preamble of the Alaska Native Brotherhood constitution, illustrating the Native leaders' commitment to acculturation into the white world:

The purpose of this organization shall be to assist and encourage the Native in his advancement from his Native state to his place among the cultivated races of the world, to oppose, to discourage, and to overcome the narrow injustices of race prejudice, . . . to preserve their history, lore, art, and virtues, to cultivate morality, education, commerce and civil government . . to improve individual and municipal health and laboring conditions . . (Preamble A.N.B. Constitution, p. 1).

However, despite this element of choice regarding their rapid and conscious adaptation into the western 
world, the economic support that resulted in the Alaska Native Settlement Act, and the complex health and wellness strengths of their people, the health status of southeast Alaska Natives continues to suffer.

As Rraus and Duffler (1979) note,". . the Alaska Natives are experiencing a steadily increasing burden of mental illness, alcohol abuse, and social disorder which far exceeds that of other American populations such as Alaska non-Natives, American Natives, and other American minority groups (p. 111).

It is important also to note that alcohol abuse amongst Native populations not only complicates and exacerbates most mental illness, but

- . most clinicians whose practice includes Native patients feels that a significant but unknown increment of physical illnesses among Natives such as diabetes mellitus, heart disease, certain neoplasms, cirrhosis of the liver, influenza and pneumonia, gonorrhea and other veneral diseases, nutritional disturbances, and complications of pregnancy are either caused or aggravated by alcohol abuse. A family unit disrupted by alcohol is a fertile breeding ground for a variety of physical, psychological and social disturbances (Kraus and Duffler, p. 149).

In summary, the history of Alaska Native health reflects a rapid movement away from the aboriginal subsistence life-style which incorporated a complex set of health maintenance practices, into a western medical care system that emphasizes medical technology. 
And undeniably the Native benefited from this medical technology, particularly in the development of chemotherapeutic agents which effectively irradicated tuberculosis. However, once this severely scarred population began to recover from the devastating effects of infectious disease, it began to experience acutely yet another epidemic, alcoholism.

In the last 20 to 30 years of Native History, alcohol abuse and its associated physical and mental health problems has threatened the survival of Native people. And the past 20 to 30 years of accelerated cultural adaptation into the western world is inextricably woven into the behavioral patterns of these destructive life-styles. How Natives and non-Natives alike approach this epidemic will influence the future of Native health and survival.

\section{Health Locus of Control Concept (HLC)}

The following discussion of the Locus of Control concept provides the background necessary to understand the written instrument (HLC Scale) that was employed in this study.

The discussion is divided into two parts. First a brief explanation of the notion of locus of control (LOC) is presented. This explanation is followed by a description of how the area-specific HLC scale evolved from the generalized LOC concept. 
Rotter (1966) published a landmark paper on generalized expectancies of internal versus external control of reinforcement and was the first social learning theorist to provide a ".: - theoretically-based, systematic study of chance and skill differences in acquisition and performance. - " (p. 2). As Rotter notes,

When a reinforcement is perceived by the subject as following some action of his own but not being entirely contingent upon his action, in our culture, it is typically perceived as the result of luck, chance, fate, as under the control of powerful others, or as unpredictable because of the great complexity of the forces surrounding him. When the event is interpreted in this way by an individual, we have labeled this a belief in external control. If the person perceives that the event is contingent upon his own behavior or his own relatively permanent characteristics, we have termed this a belief in internal control ( $p$. 1 ).

Tyler and Holsinger (1975) provide some understanding as to the differences in perceptions of locus of control between members of the majority, mainstream culture, and those of minority cultures. Their studies investigated the relationship between internal-external locus of control and such variables as self-concept and information seeking within minority and majority cultural groups. As they note,

The rationale for such a comparison is that poverty class or racial minority subjects do, in fact, have less control over environmental reinforcements; hence, they should be more external on a measure of perceived locus of control. Findings consistent with this expectation have been obtained (p. 150). 
In testing this hypothesis, Tyler and Holsinger (1975) and Echohawk (1977) investigated groups of American Indian boarding school students. The investigators administered the Nowicki-Strickland Locus of Control Scale, a forced-choice 29-item scale including six filler items. Despite other differences in their findings, all agreed that the mean for expressed externality was higher for American Indian youth than for Caucasians of the same age group.

Southeast Alaskan Natives number approximately 12,000 with the total Alaskan population approximately 400,000 , and they are definitely in the minority. And, although different in cultural patterns, language, history etc., from other Native American groups, they do have parallel underlying traditional values. As a racial minority whose members are also often poor, the findings of Tyler and Echohawk may have relevancy for this study's population.

Locus of Control and Its Links to the Health Locus of Control (HLC) Scale and Wellness

As noted earlier, wellness is an enhanced dimension of health. Ardell (1977) asserts,

High level wellness means giving care to the physical self, using the mind constructively, channeling stress energies positively, expressing emotions effectively, becoming creatively involved with others and staying in touch with the environment (p. 10). 
According to Ardell, the five dimensions of wellness are: self-responsibility, nutritional awareness, stress management, physical fitness, and environmental sensitivity. Ardell notes that self-responsibility is the pivotal factor upon which the others depend.

Townes (1984) agrees with this assertion and notes that:

The single greatest cause of unhealth in this nation is that most Americans neqlect, and surrender to others, responsibility for their own health (p. 374).

He further addresses the question of self-responsibility in matters of health when he asks: "If people do not take responsibility for their health status, is it because they can not or will not?" He comments,

'Can' refers to the ability or skill to do something, while 'will' refers to intention and effort. Intention, will, and effort seem to depend largely on where one conceives the locus of control to be in his or her life. Internal locus of control is described as seeing one-self as an active determiner of one's fate, rather than as a pawn whose behavior is controlled from without (p. 379).

The HLC Scale is an outgrowth of researchers' interest in the relationship between an individual's locus of control perceptions and his health-related behaviors. Wallston, Wallston, Kaplan, and Maides (1976) concerned themselves with the concept of locus of control and the prediction of health-related behaviors. And the HLC Scale was developed for the purpose of assisting health pro- 
viders/educators to understand the motivational orientation of their clients.

The HLC Scale as it was originally developed, was an n. - area specific measure of expectancies regarding locus of control. . . for the prediction of healthrelated behaviors. . " It was an attempt to devise a survey that would be a ". . more sensitive prediction of the relationship between internality and health behaviors" (Wallston, et al. p. 584).

In other words, in contrast to Rotter's "generalized expectancies" regarding behavior, the HLC Scale attempts to predict behavior specific to situations related to an individual's health habits and life-style behaviors. As Rotter (1966) noted, ". . . if one is seeking some practical application where every increment in prediction is important, more specific expectancy measures are necessary" (p. 59).

Trimble and Richardson (1982) also comment on the generalized expectancy versus focused expectancy when they state,

- . although a measure of a broad generalized expectancy allows a low-level prediction in a variety of situations, a narrower, more focused expectancy would allow greater prediction or a situation of the same subclass, but poor prediction for other kinds of situations that are somewhat similar. . (p. 226).

Therefore, the HLC Scale, as an area-specific measure that is narrow and focused on health-related 
behaviors, is an important emergent research area because of the possible identification of a relationship between an internal or external locus of control orientation and health-related behaviors.

However, as Wallston et al. note,

The relationship between locus of control beliefs and health-care-related behaviors appears to be, at best, highly complex.. . we wish to acknowledge that the HLC scale, in its present form, is but an initial attempt to operationalize healthrelated locus of control beliefs (p. 584).

To summarize, Chapter II has addressed five major areas that affect the communication of wellness within the intercultural health context. Specifically, this chapter has provided theoretical background in the areas of cultural values, the intercultural perspective on communication, wellness concepts, health and wellness within the Native community, and the notion of health locus of control.

In order to understand the communication of wellness interculturally, there must exist an awareness of the extent to which culture molds perceptions and communication behaviors. Culture-based communication "codes" and underlying cultural values are most often out-of-our awareness. Consequently, an intercultural perspective is necessary to aid the health professionals in viewing the world from perspectives other than one's own.

within the health context, where western medicine has been viewed as holding the answers to disease and ill- 
ness, the intercultural perspective is particularly important. In today's Native culture, where adaptation to the western world increases, so also does the incidence of the so-called diseases of civilization. These leading causes of mortality and morbidity among Alaska Natives are behaviorally-based, their solutions often defying the most sophisticated medical technology. This apparent epidemic of diseases associated with unhealthy lifestyles--diseases such as diabetes mellitus, heart disease, cirrhosis of the liver, and complications of pregnancy either caused or aggravated by alcohol abuse--may be as great a threat to Native survival as was the horror of tuberculosis.

If wellness approaches to health--that is, approaches that foster good physical self-care, using one's mind constructively, and expressing one's emotions effectively--are to be communicated effectively within an intercultural setting, it is critical that health professionals seek out those Native strengths and competencies that 1 ink traditional health-ways with modern lifestyles. And, in order to develop a wellness framework that is culturally appropriate, there must be a growing awareness of cultural value differences between Natives and non-Natives.

The next chapter presents this study's methodology. The methodology provided the means by which this study's major and general questions could be answered. 
CHAPTER III

METHODOLOGY

Statement of Design

\section{Purpose}

As noted earlier, the purpose of this study is to determine to what extent the cultural value differences between southeast Alaska Native clients and non-native health professionals influence the communication of wellness concepts. Specifically, this study will focus on the value orientation of "Man's Relationship to Health." Although value differences between Natives and non-Natives generally will be discussed, in regard to the communication of wellness, "Man's Relationship to Health" is the focus.

This study's research proposition asserts that Native cultural values and beliefs regarding health differ significantly from those of non-Natives, and these differences create major obstacles to the communication of health and wellness education. Specifically, the proposition asserts that the Native person's sense of control over health, if different from that of the non-Native health professional, will affect the communication of wellness. 
This study explores the differences in culture-based values and communication patterns that influence the communication of wellness. The methodologies and analyses employed are not rigorous to the point of allowing generalization of findings to a larger population. However, it is the purpose of this study to generate data that are suggestive, if not definitive. This study should be considered a "pilot study" which generates hypotheses for a later, more carefully-controlled study.

\section{Overview}

Utilizing the descriptive method of data collection, included were both oral interviews and a written instrument. The open-ended interview questions were generated by the author, based upon experience as a health professional and a review of both communication and wellness literature. Five Native Pretest subjects, selected because of their involvement within the Native health community, were administered the interview questions. They provided suggestions for the improvement of the schedule of questions. See Appendix B for the resultant Schedule of Questions utilized in the study.

These same pretest subjects were administered the Health Locus of Control Scale questions. Their suggestions were integrated into the original HLC scale. See Appendix $D$ for questions utilized in this study. 
Finally, the Interview Schedule of Questions was administered to twenty southeast Alaskan Natives, selected because they represented a cross-section of age, sex, and health-based employment. Ten of these twenty interviewees were health providers and they were also administered the Health Locus of Control scale questions.

In addition, ten non-Native health providers were administered the Health Locus of Control Scale Questions.

The instruments were administered in a controlled environment in order to ensure anonymity and maximize comfort level.

Interview data was analyzed employing a thematic analysis. HLC scale data was analzyed by t-testing. In addition, HLC scale data was cross-validated with interview responses and health-fair data.

\section{General Methods}

This study utilizes the descriptive method for collection of data. As Tucker, Weaver, and Berryman-Fink, (1981) note,

The overall purpose of the descriptive method is to describe events, beliefs, attitudes, values, intentions, preferences or behaviors. Unlike other data collection techniques such as library research, the descriptive method . . . involves the collection of information directly from the individuals who possess the information ( $p .90)$.

In order to elicit information that clarified and illustrated current and traditional health beliefs and underlying value orientations, both oral interview and 
survey techniques were used. As Tucker et al. note, "Some descriptive research studies combine elements of two . . . of these categories" (p. 91). And as Tyler, Hall, Taylor (1981) note, "Responses on questionnaires should usually be cross-validated with responses given in private interviews" (p. 246).

The oral interview is useful because it allows for complete and detailed information, a high response rate, use of the verbal rather than written facility of respondents, and self-disclosure of a highly personal nature.

The written questionnaire is similar to the interview in that it too gathers information directly from those who possess it. The difference lies in the fact that the interview method relies on personal oral contact with the respondent and the written questionnaire does not. Because they frequently represent an inconvenience to respondents, written questionnaires should be utilized only when information cannot be obtained through other means (Tucker, et al. p. 92).

For this current study the interview technigue was selected because of the historically-documented proficiency of Native males as rhetoricians. As Kan (1983)notes,

- - the native view of oratory was based on the fundamental Tlingit notion that the spoken word was a source of great power, capable of hurting or healing a person, of 'knocking him down' and 'lifting his spirit way up' (p. 50). 
In the interview segment many of the male interviewees did, indeed, use metaphors, stories, and descriptive examples of their experiences and feelings.

Secondly, the interview technique allowed for the detailed information regarding the interviewees' personal experience with tuberculosis and alcoholism. This kind of. personal ancedotal data is only elicited in situations where a high level of comfort exists, which for Native subjects would not be as likely with a written instrument. Finally, a high response rate did result primarily because of personal introductions made by significant members of the Native community. Once the intent of the study, that of improving communication between Native clients and non-Native health professionals, was clarified Native respondents committed themselves to working with me on this project.

In order to gain more information regarding Native orientation of "man's relationship to his health," a written instrument called the "Health Locus of Control Scale" was administered to ten Native Health providers as well as to ten non-Native health providers.

Due to restrictions of cost and time, a small number of respondents was used, all of whom were either already committed to the study or were non-Native health professionals involved in or committed to health care for Native clients. 


\section{Instruments Used}

Interview Schedule of Questions

A series of fifteen open-ended questions was designed by the author to elicit answers to the questions of how cultural value differences (specifically, man's relationship to health) influence the communication of wellness interculturally. Open-ended questions were developed in order to generate ideas and information that minimized the researcher's bias.

Five Native pretest interview subjects were administered these open-ended questions. The subjects were selected because of their leadership, knowledge, and credibility within the Native health and education community. Already committed to health issues for Native people, these subjects were willing to give feedback regarding the questions.

They suggested that with fifteen questions the researcher would be asking a lot of questions, consequently talking a lot. They stated that too often the non-Native talks more than the Native, who then becomes more and more the passive 1 istener. The pretest interview subjects assisted the researcher in choosing seven questions that seemed to elicit the maximum information (see Appendix A for the original questions and Appendix B for those chosen for the study). 
The responses to the interview questions were transcribed by the writer. After each interview session notes were immediately typed, intentionally excluding material extraneous to the subject. Interview subjects rejected the suggestions of tape recorder use.

\section{Health Locus of Control Scale Questions}

The purpose of this written questionnaire was to gather data that would help to understand the southeast Alaska Native person's relationship to his health; and further, to compare and contrast Native and non-Native responses to this HLC scale in order to ascertain cultural value differences between the two groups (see Chapter II, HLC Concept).

It is important to remember that although the original HLC Scale questionnaire was developed as a measure of expectancies regarding health-seeking behaviors, this study is primarily concerned with the issue of control as it relates to the value orientation of "Man's Relationship to his Health."

The original Health Locus of Control Scale consisted of eleven items. After the HLC scale was administered to the pretest subjects, suggestions were given by them to facilitate administration of the scale to Native subjects (see Appendix B for original HLC Scale). 
These suggestions included: 1) Modify the questions to ask the questions more directly; 2) Eliminate the original scale's question $\$ 5$ because of confusing wording; 3 ) Use "yes" and "no" answers rather than the Lickert Scale's multiple choice continuum; 4) Add a preface to the HLC Scale that underscored the goal of finding tendencies rather than absolute answers.

All of the above suggestions were incorporated and the HLC scale questions employed in this study resulted ( see Appendix C).

Validation

Because the validity studies by Wallston, et al. during the development of their original HLC Scale are not applicable to this study's modified version, validity is a concern. This study's modified and untested version of the HLC scale is, however, cross-validated by both interview questions and the SEARHC health-fair data.

In addition, interview responses were verified by interviews with five different Native elders. Considered the "culture-bearers" of their people, these elders were selected because of their first-hand knowledge of traditional life-styles and Native transition into the western world.

As Triandis (1972) notes regarding validation of underlying themes and values in a culture, "If the same 
theme appears in different instructions, or in response to different stimuli, it often is more important than if it does not (p. 82). The researcher looked for recurrent themes in elders' information that paralleled that of the study's interviewees.

\section{Study Population}

The population group from which the study subjects were selected is that of southeast Alaska Natives. The term "Native," as it will be used in this study, will refer to those people who are descended from the original people of southeast Alaska, those whose families inhabited the land for thousands of years prior to the influx of non-Natives into their lands. All Native respondents of this study are at least one-half Native.

Southeast Alaska Native groups consist of the $\mathrm{Tl}$ ingit, Haida, and Tshimpsian Indians. Within the Native community and in literature dealing with southeast Natives, the term Native refers to "Tlingit-Haida" people. Tshimpsians are fewer in number and had lived south of southeastern Alaska in Canadian territory; they moved to Alaska's Annette Island in 1884 (U.S. Forest Service, 1984, p. 1-12).

For purposes of practicality, the terms "Native" and "Tlingit" will be used interchangeably. Although there are major language and cultural differences between all 
Native groups in Alaska, the differences between $\mathrm{Tl}$ ingit and Haida and/or Aleut are not points of focus for this study. When cultural differences are discovered, they will be noted.

The term "non-Native," as it will be used in this study, refers to those people who have migrated to Alaska. The terms "white" and "non-Native" will refer to the majority or mainstream American culture.

Interview Subject Selection

A total of thirty subjects were included in this study. The interview subjects consisted of seventeen Tlingits, one Haida, and two Aleut Indians. The two Aleut subjects had migrated to southeast Alaska and married Tlingits. These two people worked with the Tlingit population as health providers and were knowledgeable regarding Tlingit life-styles. The study's subjects were divided into three groups:

1. Interview Subjects--These twenty interview subjects were selected because they met the followIng criteria: a) they represented the first generation of Tlingits to use English as their first language and to adapt to the western lifestyle. Their grandparents and parents lived the aboriginal Native life-style; b) although as children the subjects spent much time away from 
village life (because of tuberculosis treatment and boarding school attendance), they have experienced both the white and Native worlds;

c) aged 40 to 65 years, residing in both villages and towns (village Natives live a more traditional life-style than town-based Natives), and representing male and females equally, these subjects lived and worked within the whitedominated society. From this age group has come the leaders of the current Native community; d) the subjects were employees of one of the following organizations: Mt. Edgecumbe Public Health Service Hospital, the Southeast Alaska Regional Health Corporation, the Sitka Council of Alcoholism and Other Drug Abuse, or the Sitka Native Education Program.

2. Health Locus of Control Scale Subjects--The Native health providers who participated in this part of the study were also subjects for the oral interview. These health providers were selected because their work reflected a high degree of contact with the Native population. The group included three Community Health Aids (who lived in small Native villages), three alcoholism counselors, one emergency medical 
technician, one hospital mediator, one counselor, and one health instructor.

3. The non-Native health providers selected for this written survey met the following criteria:
a) 30 to 50 years of age;
b) employees of either Mt. Edgecumbe Public Health Service Hospital or the Southeast Regional Health Corporation; c) Caucasian; and d) directly involved in providing health care for Native clients. They included four medical doctors, three registered nurses, one dentist, one health educator, one emergency medical instructor, and one counselor.

Native subjects were recommended and often introduced to the researcher by Native pretest subjects or other interviewees; and/or they were previously known to the researcher because of mutual participation in Native health activities. Cooperation was often assured when the proper introductions were made.

Non-Native subjects were known to the researcher because of previous professional contact. Cooperation was probably based upon their commitment to Native health.

The researcher recognized that potential biasing of responses might occur when subjects had had a previous relationship with the researcher. However, within the Native community suspicion of non-Natives is decreased when non-Natives have relationships already wellestablished. 


\section{Procedures}

This researcher conducted all aspects of the research. The subjects were told that not only was the research to be used for a Master's degree thesis but that it would be used in other ways (such as intercultural awareness programs) that would promote improved communication between Natives and non-Natives.

As the National Arctic Health Science Policy notes:

Many people living in the Arctic, particularly Native people, feel that they are 'over studied.' They feel that they help scientists too often to achieve the researcher's goals without ever being the recipients of the information or the beneficiaries of the project. They resent being regarded only as subjects of experiments, and they feel that their health, reputation, and privacy are not being adequately protected (American Public Health Association, p. 19).

Anonymity was assured and subjects were advised that the research results would be made available to them and their health agencies/organizations.

All interviews were conducted in one of three places chosen by the interviewees: the interviewees' home, office, or a restaurant. All interviews were at least one hour long, most lasting from two to four hours.

The written survey was administered to the Native health providers immediately after the schedule of interview questions had been completed. The non-Native health 
health providers answered the survey during their work hours at the Mt. Edgecumbe Public Health Service Hospital.

\section{Methods of Data Analysis}

Interview Data Analysis

A "thematic analysis," which involved an informal review of the responses and their division into useful categories, was undertaken. The categories which were generated by the responses fell into two major areas: First, data relevant to the process of communication, including what Hoopes has called the "cultural code" --not simply non-verbal communication cues but behaviors as subtle as silence, the meaning of space, or failure to smile; secondly, data that is related to value orientations of Natives, with a specific focus on responses that helped uncover clues regarding "Man's Relationship to Health." General value orientations such as "Group versus Individual" and "Age versus Youth" were also sought.

The communication process category most often included responses generated by interview questions \#3, 4, 5, and 7. Value orientation-related responses were generated by \#1, 2, and 6 (see Appendix B). Because of the large number of responses and their complexity, some responses were arbitrarily assigned a category. As Hall (1977) noted, ". . the various facets of culture are interrelated. . " (p. 16). 
However, these two categories were useful because they provided a framework that allowed for the identification of these often subtle values and communication processes.

\section{HLC Data Analysis (t-test)}

A $t$-test was performed on HLC-generated data (see Chapter IV).

\section{Summary}

Utilizing the descriptive method for collection of data, both oral interviews and a written instrument were included. The study included 30 Native and 10 non-Native subjects for oral interviews and a written survey. A thematic analysis was undertaken to evaluate data obtained by the Interview Questions and $t$-testing was performed on the HLC scale findings.

The next chapter presents the results of the interview and HLC scale questions. 
CHAPTER IV

\section{RESULTS AND DISCUSSION}

The following is a summary of the findings generated by specific interview and survey questions asked of selected Native and/or non-Native subjects (see Methodology, Chapter III, for subject selection criterion). This discussion is divided into five sections, based on the results of the interview and HLC scale questions. The five data categories include: 1) Transitional lifestyles; 2) Native health and wellness indices; 3 ) what non-Native health professionals should know about Natives and their culture; 4) Health counseling; and 5) Data related to the value orientation of "Man's Relationship to Health."

\section{Transitional Life-styles}

The following is a report of the interviewees' responses to the first interview question:

"What are some of the differences between traditional Native life-styles and today's modern times that you think have affected Native health?" (see Appendix B). The following responses are listed in order of frequency: 
Twenty out of twenty respondents stated that health was affected by the move from a subsistence life-style to a life based on a cash economy. Each respondent noted that the subsistence life-style affected all areas of life, including physical activity, nutrition, relationships with others, and relationship with the natural world. The shift towards store-bought foods, television, and a sedentary way of life, combined to create illness and disease (see Chapter II for more information on subsistence).

Twenty reported that the move from Native foods to "white man's food" was the most important factor affecting Native health today. The respondents all reported that obesity and dental disease within their youth was disturbing to them. Each respondent talked of the nutritional value of salmon, seaweed, deer meat and other "natural" Native foods as they compared to white sugar, flour, and prepackaged foods.

Eighteen reported that traditionally Natives were physically active with subsistence maintenance activities. The sedentary life-style based on office jobs and television-viewing was described as a negative affect on heal th.

Twelve reported that Natives had learned to adjust to the treatment of infectious disease. They had learned to use the medical system. However, they expressed frus- 
tration with the life-style-related health problems such as alcoholism and its side affects that don't seem to be amenable to such treatment. They reported that the apparent dependency on the medical doctors and medication stems from having learned to treat infectious disease. Eleven reported that a major change in Native life came when the influx of whites seemed to be never-ending. They became a minority in their own land. This change affected health, according to them, because self-esteem and pride in being Native declined as contact with whites increased.

Eleven reported that the move away from Native education that occurred within the traditional extended family towards the western-based boarding school education created a major shift in thinking that eventually affected mental health. Instead of learning how to fish, hunt, and preserve subsistence foods, the young people learned to speak English, to cook western food, clean, and to function in the workplace. Although these were valuable skills in the white world, the young were left ignorant of how to survive in the natural world.

Six reported that, in general, the adaptation into western culture was too rapid. They believed that the transition was traumatic because they lost too much of their culture too fast. This rapid transition left them ill-prepared to make positive health choices. 
The following responses numbered four or less but are relevant to the question and are therefore included.

Four reported that at one time self-esteem was high among the Native clans. Today's low self-esteem, particularly among the youth, was reported to be directly contributing to destructive life-styles.

Three reported that responsibility for health was traditionally shared by community members. However, with the advent of infectious disease control, often the doctors and hospital took on such importance that the individual and community became less and less the focus.

To summarize, the most frequently reported cultural changes that have affected Native health included: 1) move from subsistence to cash economy-based lifestyle; 2) the move from Native foods to "white man's foods;" 3) the move from a physically active life-style to sendentary behaviors; 4) the need to change from melically-based treatment of infectious disease to treatment of behaviorallybased and 1 ife-style-related disease and illness; 5) becoming the minority in their own 1 and; 6 ) the move away from "Native" education towards the boarding school education.

One respondent summed up her answer to this question by saying that it was difficult for her not to idealize the traditional life-style. Although she recognized that life then was often difficult and the weather harsh, she 
remembered fishing with her grandfather, picking berries with her grandmother, and listening to her uncle's stories to be the happiest times in her life. Her current concerns such as mental stress, obesity, diabetes, and political battles reflect a very different life-style.

The next section presents the characteristics of healthy Natives as reported by interviewees.

\section{Native Health and Wellness Indices}

Native health behaviors that reflect strengths and competencies are termed "health and wellness indices."

The second interview question elicited answers related to these health and wellness indices. The question asked: "What do you think are some characteristics of a healthy Native person in today's society?"

The following responses are 1 isted in order of frequency:

Seventeen out of twenty respondents stated that a healthy Native takes time to participate in subsistence activities. These activities included fishing, hunting (as well as cutting, drying, and smoking meat and salmon), and berry-picking and preserving. The activities also included healthful components such as physical activity, being part of the land and sea, eating healthful foods, and sharing with others. As noted in background 
information, subsistence is a broad concept that has always been central to Native survival and wealth.

Fifteen noted that healthy Natives have strong family and clan relationships. They "know" their position in the clan structure. In spite of rapid acculturation, the moities of Eagle and Raven, as well as clan houses, continue to be represented in music and dance and recognized in daily interactions. Strong nuclear and extended family relationships within the Native community help create the individual's sense of belonging and establish one's place in the whole system.

Fifteen noted that leading a non-addicted life-style was necessary for healthful living. Most noted that the addiction pattern referred to was alcohol abuse. They noted that other drugs were abused more by young than the middle aged or elders. Compulsive eating and cigarette smoking were infrequently mentioned as part of an addicted life-style.

Twelve noted that healthy Natives eat more Native foods than "white man's food." Nutrition was considered important to adults as well as children. But most people mentioned children's dental disease, and other health problems related to a high sugar intake. Frustration was expressed over the fact that many Native children today have not grown up on Native foods and therefore do not have a taste for such things as "stink eggs" 
(fermented salmon eggs considered a delicacy as well as a body cleanser) or other Native foods. Some grandparents kept dried seaweed around in order to create an example for the children. Many middle-age persons are now, for the first time, learning from other Natives about the subsistence practices of preparing and preserving Native foods.

Twelve noted that an active spiritual and church life is essential to good health. When talking about living a non-addictive life-style, the Church (Russian Orthodoxy, Protestantism, and many of the fundamentalist churches such as Church of the Nazarene) was always mentioned as the cornerstone of sobriety. Several persons noted that they couldn't think of any recovering alcoholic that wasn't a Christian.

"Pride in being Native" was mentioned by ten respondents. This pride was a natural part of the aboriginal Native's life. The English translation for Tlingit is "The Real People." Two alcoholism counselors noted that "false pride" gets in the way of the recovery process. But pride in being Native is associated with higher self-esteem and necessary for recovery.

Seven noted that a good education was necessary for a Native to survive in the white world. One collegeeducated interviewee noted that $\mathrm{h}$ is father said education was likened to climbing a ladder: "The higher you climb 
the more looking back and evaluating what's behind you can do." As noted earlier in the Preamble to the Alaska Native Brotherhood (p. 37), education historically played a major role in the conscious acculturation process, and was considered by Natives to be a major force in improving their lot in the white world.

Seven reported that biculturality was necessary in order to function in the white world. The major factor discussed was the ability to maintain one's "Nativeness" while learning to understand how whites think, how they relate, and what they mean when they communicate. One interviewee noted that when he is with whites he makes jokes. He has learned to understand the kind of humor whites usually enjoy and he uses it himself. When he is laughing with whites he feels a part of their group. However, several respondents noted that this biculturality is considered a fine line to maintain. They described the "Apple Indian" concept that applies when a Native fails to walk this line. "Red on the outside but white in the inside" describes the Apple Indian and is one of the greatest insults an Indian can receive.

Eight noted that a strong self-concept is necessary for good health. Although the group and its sanctions and encouragement were considered important, "self" was mentioned throughout the interviews. A strong self-concept was linked to self-esteem. The self is a concept not for- 
eign to Tlingits. Self-discipline, self-denial, and self-purification were parts of becoming a Tlingit.

Less-often mentioned characteristics included participation within Native organizations, developing a variety of interests, and learning about Native culture from grandparents and other Natives.

In summary, Native health and wellness indices as reported by Natives reflected some basic cultural values. Time for subsistence activities, strong family and clan relationships, as well as learning to live a non-addicted life-style were the most-often reported characteristics of a healthy modern Native. These behaviors reflected a strong group orientation as well as a harmonious relationship to nature.

Other responses were: Attention to good nutrition as reflected in Native foods, a healthy spiritual life as reflected in church and Brotherhood and sisterhood activities, pride in being Native, and a strong self-concept. These characteristics also reflected a group orientation. A good education was seen as a mechanism to enhance these qualities. Biculturality also was viewed as a vehicle to move Indians into white society without their losing their "Indianness."

It became clear that the respondents' concept of "health" was broadly defined -- and included social, psychological, as well as physical factors. 
The following section presents data related to what non-Native health professionals should know about Natives and their culture to improve health/wellness education counseling.

What non-Native Health Professionals Should Know about Natives and Their Culture

The following discussion provides an in-depth look at Native culture and communication behaviors that Native respondents reported were different from those of non-Natives. In addition, they provided culture-based information which they perceived as critical to the understanding of their people as a culturally-different group. Together these findings provide an understanding of the face-to-face interaction that occurs between Native clients and non-Native health professionals.

The following section is divided into two parts. The first part will present the communication-based responses. The second will focus on the culture-based responses. The responses are a compilation of answers to numbers three, four, and five of the interview questions:

1. "What do you think non-Native health professionals should know about Natives and their culture to be better health counselors?"

2. "What do you like most about non-Native health professionals?" 
3. "What do you dislike most about non-Native health professionals?"

\section{Communication-Based Responses}

Eleven out of twenty respondents described condescending attitudes, or "talking down" to Natives, as the thing they like least about non-Native health professionals. When asked for examples of that kind of behavior, several respondents reported that repetitions of the same directions and/or talking louder and louder were indications that the non-Native "didn't think I had a brain in my head," or "didn't think I spoke English."

Ten stated they disliked the "I know best" approach to health counseling. Several respondents reported that they preferred options and alternatives rather than absolute answers.

Ten reported that Natives learn best through observing and that diagrams as well as words were important for complex explanations.

Seven reported that Natives are generally less verbal than non-Natives. They suggested that non-Natives might allow for more pauses in the conversation, allowing more chances for Natives to speak.

Seven respondents reported prejudice, subtle but sure, as a problem. When asked for an example, one 30 year-old hospital housekeeper/alcohol counselor reported a friendliness by non-Natives in the doctor's office or in 
the hospital. But noticed that when he met the same person in a public or social situation he would feel ignored. He desired to be treated the same anywhere.

Seven noted that non-verbal communication cues are often different between Native and non-Native. The village Health Aids warned that Natives may not use direct eye contact and that this should not be interpreted as distraction or not listening. Several respondents noted that they had learned to look white people in the eye but that it was not comfortable.

In addition, these respondents noted that Native facial expression may not seem expressive to a non-Native. This seeming lack of facial expression is not necessarily due to any lack of understanding. Rather, it is "our way."

They noted also that touching is more acceptable to young people than elders. Elders need and expect their personal space and casual touching is not generally desired.

Six noted they appreciated these health professionals who take an interest in village activities--things important to Natives. An example given was that of of attendance at local basketball games. An interest in basketball games denotes an interest in the people and their values. Basketball is central to much of village social life. Attendance shows that the non-Native knows 
that there was something of importance going on in the community even before the health professional arrived.

six respondents noted that the use of big words rather than basic English creates a communication gap rather than understanding. Two respondents stated that they resented the use of big words because it further distanced them from the health professionals. Other respondents merely noted that the use of complicated medical terms was confusing.

Five reported that a show of respect for Natives was important to communication. Respect could be shown, they added, by taking an interest in community activities, asking about extended family members and by not acting too casual.

Five reported that diplomacy was important. Diolomacy is essential because of the closeness of the Native community. The respondents noted that if you insult one Native, you've insulted others close to him/her. Diplomacy was described as "sensitivity to Natives" and "caring about Native things." It was also reported that "small talk" and "chatting" were ways to practice diplomacy. Five reported they appreciated a show of respect for elders, the culture-bearers. This could be shown by attending lunch at the village Senior Center and respecting elders' needs for space. 
In addition, the following responses were made by three or less interviewees. Although few in number, these communication-based factors are important to the process of communication and are therefore listed:

Three reported that length of stay for itinerant health professionals in the village is important. A week-long stay versus a few days indicates a commitment and involvement not shown otherwise. These same respondents indicated that health professionals who continued to work with them over years were appreciated.

Two reported that 1 istening was important. They indicated that when non-Natives were very verbal, they could not be 1 istening.

Three noted that very often a Native will say what he/she thinks the non-Native wants to hear. They stated that Natives have felt negatively judged for a long time and avoid these evaluations when they can. One respondent reported that Natives are often not considered "good historians" when answering the doctor's questions. The respondent noted that this might be due to expectations regarding such things as duration of the problem. If the Native client believed having the problem for a long period of time reflected poorly on him, he might shorten the duration.

Two noted they disliked having traditional ways ignored or scorned. One elder noted that most Natives do 
not mention any of the traditional cures to non-Natives because of the expectations of ridicule.

Two reported that elders are bilingual and it takes them longer to respond because of mental translating. Two mentioned they disliked being treated like a child and especially disliked observing elders being treated in that way. Example was that of patting an elder on the head, which is interpreted as a condescending act.

Two stated they appreciated someone who was enthusiastic about health teaching and sharing information. This interest indicated that they believed that the Native client was capable of learning. This was a sign of respect and the opposite of a condescending attitude. Two respondents noted that the indirect style of communication was normal for Natives. Because it is uncomfortable to "jump right into the subject," chatting and small talk were suggested to set the stage for further discussion about personal matters.

Two reported that they disliked having their opinions about their own health problems ignored.

One woman reported that she disliked not being given details about her upcoming surgery. She felt she needed more information but didn't know what questions to ask. She indicated also that when with the doctor she felt nervous and forgot her questions. 
Two reported that they liked feeling good about themselves when leaving a counseling session. "Feeling good about themselves" (feeling "ok") was not defined except to say they felt hopeful regarding the problem and would probably return for further appointments.

\section{Culture-based Responses}

This second section presents culture-based responses to the above stated interview questions. Of the twenty respondents:

Eighteen reported that the subsistence life-style is something non-Natives should understand. Important aspects to this subsistence life-style included the Native foods that nourished their bodies, the physical fitness necessary for such an active life-style, and the feeling of being a part of nature that nourished their spirit.

Twelve noted that non-Natives should understand Native history and their groups' adaptation into white culture.

Six noted that more research was necessary to 1 ink old ways to modern life-styles. Many people described the recent "Nutritional Analysis of Native Foods," developed by nutritionist Helen Hooper of the Mt. Edgecumbe Public Health Hosptial, as an example of this kind of research.

Five thought that non-Natives should understand that survival continues to be a major issue for many Natives -that the survival factors such as obtaining a job and 
other economic resources in a white-dominated society might take priority over some of the suggestions made by health professionals regarding a healthy life-style.

\section{Summary}

The responses were divided into two basic categories, that of communication and culture-based responses. Culture-based responses focused on the importance of understanding both the subsistence life-style of the past and today's Native adaptation to white culture.

Communication-based responses included twenty-one concerns or suggestions that related to dyadic interactions between Native clients and their non-Native health professionals. It became clear that Natives perceived communication factors to be of great concern, and that differences in communication behaviors of the two groups could easily be negatively evaluated.

The following is an abbreviated list of the major concerns reported:

\section{Communication-based Concerns}

1. Condescending attitudes and behaviors.

2. Authoritative attitudes.

3. Native learning strengths of 1 istening and observing rather than verbalizing.

4. Allowing for pauses in conversation to allow for less verbal clients to speak. 
5. Being aware of prejudical behaviors in and outside of work settings.

6. Differences in non-verbal communication cues and correctly interpreting these.

7. Understanding that activities of the health professional are only one part of a Native person's 1 ife.

8. Avoidance of big words when basic English could suffice.

9. Showing respect for Natives and the Native community.

\section{Culture-based Concerns}

1. That non-Natives understand subsistence and the multivariate role it plays in many Natives' lives.

2. An understanding of the history of Native people.

3. An understanding of ways in which traditional life ways can be linked to contemporry lifestyles.

4. An understanding that basic survival in the white-dominated society continues to be a major issue for many Natives and their families. 
Wellness/Health Counseling

The following section presents responses by subjects regarding actual health/wellness counseling sessions experienced by Natives. This seventh item of the Interview Schedule of Questions stated:

"Please give an example of a health counseling situation you have been in and explain how it was or was not helpful." "

The following responses are listed in order of frequency:

Six respondents noted that alcoholism counseling had been helpful but only over a long period of time. The respondents noted that counseling required that the counselor a be non-judgemental person with a high tolerance for inconsistency.

Four respondents reported that their doctor had counseled them about high blood pressure. Respondents reported that decreasing salt in the diet was the most difficult aspect of counseling suggestions. One respondent reported that he became frightened when the doctor indicated alarm about his high blood pressure. He stated that he immediately started to rethink his exercise patterns and diet. And he also started to decrease the salt in the brine he used for smoking fish. 
Three reported that counseling regarding stressreduction was helpful. Information regarding signs and symptoms of stress, including headaches, over-eating, and stomach pain was reported as helpful.

Three reported that weight-loss counseling had been unsuccessful. Respondents reported that the problem was chronic and patterns seemed impossible to change, regardless of counselor's suggestions.

One respondent reported that she had been counseled by her doctor regarding cystic breast disease. She stated that she had looked up information regarding dietary treatment of the condition, reported her findings to her doctor, and was pleased that her doctor agreed to followup on the information. This cooperation between client and doctor resulted in a dietary regime which resolved the problem. The client felt she played a major role in her recovery.

One client reported that he and his doctor had been unsuccessful in helping him to quit cigarette smoking. The respondent felt he was responsible but that he was not ready to quit.

To summarize, health counseling was described by respondents and included health problems such as hyptertension, alcoholism, and obesity. 


\section{Data Related to "Relationship to Health" Value}

The following discussion addresses the value orientation of "Man's Relationship to Health." The underlying issue for the value is the question of who or what is in control of a person's health. This data addresses whether or not Natives feel in control of their health. As noted earlier, whether or not clients perceive that their health is contingent on their health behaviors plays a major role in health and wellness counseling. The following discussion presents the combined results of the Health Locus of Control Scale and interviewee questions. The discussion consists of two parts.

First, the interview responses to the question of "Who or what is in control of a Native person's health?" will be reported. Second, results and discussion of the HLC Scale will be presented. A summary will clarify the impact of the data.

Interview responses to the question of who or what is in control of health.

The following is a report of interview responses to the sixth question included in the Interview Schedule of Questions:

\footnotetext{
"Who or what do you think is in control of a person's health? God, fate, luck, the person themselves, parents, others, etc.?"
} 
Seventeen out of the twenty respondents answered that persons themselves are ultimately responsible for their own health. However, six of those respondents also reported that health resources including the family and community, played major roles in health status during childhood.

Seven responded that during epidemics, doctors and the medical personnel were responsible for Natives' health. Four respondents reported a belief that major life and death matters were controlled by God.

Interestingly, three respondents noted that mothers and people in leadership positions often are trained to put others first and to think about themselves and their own health secondarily. One leader, and head of a traditional house, reported that the demands placed on him by his people took priority over any personal activities such as jogging or going fishing. Group responsibilities played a powerful role in determining his daily activities.

One respondent discussed shamanism as she had been informed by her mother and grandmother. She reported that "Some people in the past and still today believe they may have been witched--particularly if the doctor can't diagnose the problem." When asked if this belief was mainly by the elders she said "no;" that younger people say it 
also, but more casually. It is, nevertheless, one possible answer to the unknown.

Three respondents reported that governmental agencies have played such a major role in Native health care that often Natives are dependent upon doctors and medication, using the system to an excess. One respondent reported that when Natives have no input to an agency or program, they will be more apt to misuse it.

Al so addressing the overuse of the medical system, two respondents suggested that health education be made the focus of health care. They noted that because of the rapid adaptation to the modern world of fast food, sedentary jobs, and stressful town-based lives, Natives need to learn how to make constructive, rather than destructive, health choices.

In addition, several respondents noted that environmental problems of today are too big to be controlled by the individual. However, the respondent added that basic health through fitness, adequate diet, and stress-control are areas for the individual to manage.

\section{HLC Scale Responses}

The following section is divided into two parts. The first will report the results of the HLC scale questions. The second part will consist of an analysis of the results. 
The results of the HLC Scale questions assist in answering the question of: Who or what is in control of a Native's Health? The data also suggests some perceptual differences between Native and non-Native health providers concerning the issue of control as it relates to health.

The internality-based items (see Appendix B for \#1, $2,7,9$, and 10$)$ are framed in a way to ascertain whether the respondent perceives that health status is contingent upon his behavior and/or his relatively permanent characteristics. When the respondent responded positively to such an item it was considered a belief in internal control.

In contrast to internal control, external control is the individual's perception that a result (i.e. health) follows some action of his own but is not entirely contingent upon his action. And, as Rotter (1966) notes, given this lack of direct responsibility for the result, ". . It is typically perceived as the result of luck, chance, fate, as under the control of powerful others, or as unpredictable because of the great complexity of the forces surrounding him" (p. 1). Items \#3, 4, 5, 6, and \#8 are framed in such a way as to ascertain whether the respondent perceives his health to be mostly under the control of external forces rather than his own. When the respondents answered positively to said items it was considered a belief in external control. 
The internality-based items are concerned with definite personal behaviors for which the individual is responsible. Examples include: 1) taking care of yourself; 2) getting the proper exercise, rest, or right food; and 3) getting sick because of something you have or have not done for your health. In three out of five internalbased items, Natives answered more positively than did non-Natives (see Appendix D). In two of the five items Natives answered nearly identically to non-Natives. The externality-based items are concerned with health being contingent upon: 1) just plain luck; 2) doing only what the doctor tells you to do; 3 ) mostly a matter of good fortune; 4) dependent on strange diseases; and 5) the inevitability of getting sick. In all but \#6 the non-Native health professionals answered more positively to these externally-based items than did Native health providers.

As noted earlier, Lantis (1963) stated that ". . southeast Natives have never been indifferent to disease and have not taken it for granted, as do so many races of fatalistic tradition. . " (p. 6). The control of disease has not been a foreign idea and Natives have traditionally and contemporarily taken advantages of old and new medical cures.

Therefore, it is possible that externality-based item $\# 6$ was answered more often positively by Natives than 
non-Natives because of the wording "strange disease around." Such diseases experienced by the majority culture, but not known or experienced widely by Natives, could be considered as under the control of powerful others such as governmental health officials.

Unlike the other externality-based items, item \#6 was geared not to ascertain attitudes regarding fatalism or belief in good fortune but rather the subject's perception of the power of "strange diseases around." For these reasons \#6 stands out from the other four external-based items.

\section{Discussion}

The findings are significant in terms of suggestions rather than absolute answers. It is interesting to note that in three out of the five internality-based items, Natives responded more positively than non-Natives. Given the findings of Tyler and Holsinger (1975) and Echohawk (1977) asserting that expressed externality is higher for American Indian youth than for Caucasians of the same age (adults were not tested), this study's internality tendency of Natives is surprising.

As noted earlier, Gurin et al. (1969) had suggested that "real life" for many minorities and the poor are full of barriers for which those groups have little actual con- 
trol. He distinguished personal control from ideological or environmental control and suggested that although minorities and the poor may have a sense of their own personal power, in regards to the majority culture and the greater societal factors, these group members perceive little control. It appears that item \#6 reflects these environmental factors and personal efforts of the individual may not be perceived to be powerful enough to counter such forces.

However, in terms of personal life-style behaviors, Native health providers clearly perceived themselves to be in control. Exercise, nutrition, and generally taking care of oneself are all factors that were perceived to be within their control. The results suggested that the Native health providers felt more strongly than their non-Native counterparts that these factors are more important to their health.

In terms of luck, chance, or good fortune, it appears that Natives do not consider their health to be contingent on such factors. Although the differences are not statistically significant, Natives answered negatively to externality-based items more often than did non-Native health providers. These findings correlate with Lantis' (1963) assertion that southeast Alaska Native people are not fatalistic in their beliefs about health and disease (p. 6). 
In addition to this nonfatalistic stance, the data suggests that Natives subjects in this study have developed a sense of control beyond what one might hypothesize, given their disease history and dependent relationships with various governmental agencies such as the U.S. Public Health Service and the Bureau of Indian Affairs. These governmental agencies are known to foster a dependency that is inconsistent with a feeling of control over one's fate (Echohawk, 1977, p. 47).

This author feels that at least part of the answer lies in the experience with the alcoholism recovery process. At least three out of the ten Native health providers were recovering alcoholics. Three others were alcohol counselors directly involved with clients and their recovery process. All have had direct contact with family and community members who have been through this same recovery process.

The alcohol recovery process is mostly internal. Alcohol counselors and friends can sometimes lead the individual to resources. But the individual must personally initiate and follow-through with this lengthy and often mentally and physically painful process. A successful recovery process empowers clients in a way that few other experiences can.

Most non-Native health providers have not experienced alcoholism recovery in a personalized way. Rather, 
their experience is usually one of frustration and resentment regarding their client's alcoholic behaviors and recidivism in alcohol treatment programs. This difference in personal experience with alcohol recovery may promote a perceptual difference critical to one's sense of control. To summarize, the HLC scale results indicate that Native health providers have expressed internality equal to that of non-Native providers, and in three of the five internality-based items, Natives responded more positively than non-Natives.

Regarding the externality-based items, it appears that Natives and non-Natives alike generally feel that good health is not a matter of good luck, fortune, or chance. However, with the exception of $\# 6$, Natives did answer slightly more neqatively than non-Natives showing a stronger expressed externality for non-Natives than Natives.

This data suggests that Native health providers feel that their health status is contingent on their health behaviors. This perception that health behaviors are within the power of the client are consistent with Gurin et al.'s suggestion that minority people can have a sense of their personal control that is not necessarily extended to the greater society. Externality-based item $\$ 6$ which refers to "strange diseases around," could be interpreted 
to reflect the greater society which is outside the Native's control.

To summarize interview and HLC scale subjects (who included a cross-section of the Native population in age, residence, and sex), nearly all responded that they felt they were directly responsible for their health.

\section{t-testing of HLC Data}

Although the t-value of 1.10 is not statistically significant in the direction that was predicted from the theoretical discussion, the data do seem to support a possible systematic difference between the two groups wherein Natives are more internally-oriented than non-Natives. The researcher did not formally hypothesize that Natives and non-Natives would differ on internality in any definite way. However, because of Native experiences with dependency-promoting governmental agencies, the researcher questioned whether Natives would be as internalityoriented as non-Natives.

Considering their value orientation of individualism and self-reliance, the researcher expected non-Native health professionals to be internality oriented.

Therefore, the degree to which Natives expressed internality was surprising. 


\section{Data Validation}

\section{HLC Data}

The responses to the HLC scale questions of this study point to a strong expression of internality regarding personal control of health for Natives. Number six of the Interview Schedule of Questions (see Appendix D) indicate that the majority of the subjects believed that the responsibility for health lies with the individual (not God, fate, or the doctor). This perceived ability to control health is consistent with the HLC scale results that showed a strong internal orientation of Native subjects.

In addition, SEARHC Health-Fair data, obtained from the health corporation itself, helps to validate the Native perception that the responsibility for health lies with the individual.

The researcher took part in the $1984 \mathrm{Tl}$ ingit and Haida Convention, providing follow-up counseling during the end-point of a SEARHC-sponsored health fair screening process. During the initial Health Fair activities the participants filled out two questionnaires (see Appendix F). Important to this study's focus on "Relationship to Health," one question was included two times in the questionnaires. The question was:

"Who has the major responsibility for your health?" 
Out of the fifteen Natives that responded, twelve answered "myself" and three answered "doctor." Of these health-fair participants, many were executives of the Tlingit-Haida profit corporation. These individuals lived a very different life from village or small-town Natives, traveling to major cities, living in hotel rooms, and spending time in hotel lounges. The "fast life" was discussed and participants reported that weight control, stress management, and fitness activities seemed almost impossible to incorporate into their hectic lives.

These respondents were mostly married, employed, earning $\$ 25-40,000$ and college-educated. This demographic data contrasts greatly with the majority of Natives who struggle to survive in villages and small towns of southeast Alaska. This population sample has the characteristics of a highly acculturated group, and are not representative of the majority Native population.

\section{Interview Data}

In order to provide background information for the researcher, five elders (selection based upon criteria noted on p. 6) were interviewed regarding their personal experiences with the transition from traditional to modern life-styles. They were asked the first question of the Interview Schedule of Questions: "What are some of the differences between traditional Native $\mathrm{I}$ ife-styles and 
today's modern times that you think have affected Native health?" Their answers paralleled those reported by interviewees (see p. 60) and consequently verified the interview data.

\section{Chapter IV Summary}

This chapter has presented the data that resulted from 1) The interview questions, and 2) The HLC Scale questions (see Appendices $B$ and $D$ for specific questions). The data was divided into five categories:

1) Transitional life-styles; 2) Native Health and Wellness indices; 3 ) What non-Native health professionals should know about Native and their culture; 4) Health counseling; and 5) Data related to the value orientation of "Man's Relationship to Health."

The major themes that surfaced were as follows:

1. The significance of subsistence activities in health maintenance for contemporary Native clients.

2. The communication problems that result from health professional's lack of cultural awareness.

3. The difficulties in communicating behaviorallybased health education.

4. Native respondents' perceptions that good health is within the control of the person themselves 
(internality-based perceptions that address the value orientation, "Man's Relationship to Health").

The following chapter discusses possible applications of the intercultural perspective to communication problems reported by Natives. 
CHAPTER V

APPLICATION OF THE INTERCULTURAL PERSPECTIVE TO PROBLEMS IN INTERCULTURAL COMMUNICATION

AS REPORTED BY NATIVE RESPONDENTS

This chapter will present the ways in which the intercultural perspective may be applied to communication concerns reported by Native subjects. Because the communication of wellness is this study's central theme, it is critical that these problems be addressed.

As noted earlier, the intercultural perspective is interactive, difference-based, processual, and humanistic. These characteristics or approaches of the perspective will be applied to each of the four most frequently reported communication concerns: condescension, authoritative approaches, differences in learning styles, differences in verbalization. It is hoped that through this analysis, insights into possible solutions will result.

The most frequently reported communication concern was that of non-Natives' condescending attitude. This attitude was described as talking down to Native clients 
by repeating the same thing over and over again and/or talking louder and louder, giving the client the subjective sense that non-Native health professionals "don't think I have a brain" and/or "don't think I speak EngIish."

These communication behaviors may have resulted from misinterpretations of communication cues. As noted earlier, communication cues and behaviors are culturallyconditioned and largely out of our awareness. Consequently, these basic ways that we learn, communicate, and/or perceive reality differ from culture to culture. The difference-based intercultural perspective asserts that these cultural differences can be challenges rather than threats. For example, if a Native client utilizes culturally-based indirect rather than direct gaze, and/or shows less facial expression than normally shown by non-Natives, the non-Native might interpret the cues based on non-Native, not Native, cultural patterns. The interpretation might be that of inattentiveness or lack of interest, not at all representative of the actual Native experience.

If, on the other hand, the health professional was interculturally aware, there would be no need for negative evaluations of the other's communication behaviors. Utilizing the difference-based approach, the culturally 
aware health professional would be challenged rather than threatened by these potentially ambiguous cues.

In addition, the processual approach allows for both dyadic members to create and recreate meaning. The feedback circle, including the client's verbal and non-verbal responses, is crucial to the communication of wellness. During this process there is a focus on the client's internalization of health information and translation of it into some meaningful action.

The second most frequently reported communication problem was that of the authoritative approach to solving health problems. The humanistic approach contrasts with the authoritative stance frequently taken by the medical community. "The doctor knows best" attitude implies that the health professional holds the keys to health. As noted earlier, this might have been an appropriate approach when infectious disease was the major threat to health and chemotherapy cured tuberculosis. At that time, as Native subjects noted, the doctors were in control of their clients' health.

However, today's epidemic of life-style-related disease seems to defy chemical or technical cures. Today's emphasis on prevention returns the responsibility and control for learning new and healthier life-style behaviors to the client. 
Consequently, a focus on the individual client's potential for change appears more critical than technical information held by the health professional. Health problems that are embedded in daily habits require a consideration of the whole person--including body, mind, and spirit.

The humanistic approach asserts that subjective experiences of the client are legitimate. The authoritative approach sets a stage for power differences in the dyadic communication. If one dyadic member has the answers, the other member is a passive recipient of them. Within the humanistic context, there is mutual respect and equal power because both members have important roles to play. The subjective "ok" feeling that subjects reported may result when a balance of power exists.

The third most often reported communication concern was that of Native learning styles that differ from non-Natives. Interview subjects noted that Natives learn better by observing and listening than by verbalizing. Utilizing the intercultural perspective, this difference would be accepted as basic to the success of communication and steps would be taken to utilize these observations and listening strengths.

As suggested by interview subjects, diagrams and illustrations could be used to explain complex concepts. The difference-based approach would recognize the validity 
of such learning styles. This approach does not deny the need for verbal feedback by the non-Native health professional but it does ensure that different needs of the client are also being considered.

Closely associated with the Native strengths of observation and 1 istening is the fourth most reported communication concern, that of the verbal differences between Natives and non-Natives. Native health providers reported that Natives are more comfortable with silence than are non-Natives. This difference often results in the non-Native quickly (or so it seems to the Native) jumping into the conversation, always appearing too talkative, and/or inattentive to what the Native has to say. The health providers suggested that non-Natives try to allow more pauses in the conversation. Silence allows for feedback. Constant verbalizing decreases the opportunity for the more reticent member to speak.

The processual approach to communication allows for these silences and the time necessary for the process. A linear approach, in contrast, emphasizes the amount of Information that can be "effectively" squeezed into an allotted time period. In other words, it is often guantity and not quality that is encouraged.

Pauses in the communication also allow for the bilingual needs of elders and for the Native emphasis on diplomacy. In addition, interviewees reported that 
Natives place a high value on diplomacy, including avoiding hurting feelings or insulting others. However, diplomacy is not a concept well-understood by mainstream American culture. In contrast, it values directness and honesty, and often interprets indirect approaches as evasive. Diplomacy may also require some additional time, conversational pauses, and/or "small talk."

Because the traditional Natives' indirect style of communication require more time than do "direct" approaches, non-Natives often become frustrated, especially in health-care facilities committed to efficiency. More circular approaches seem to distract from "the point." The difference-based and processual approaches validate the indirect approaches to communication and allow for the time necessary to address these needs.

The following section addresses the intercultural communication training for health professionals.

\section{Intercultural Training Based on the}

\section{Intercultural Perspective}

Intercultural education for health professionals is desirable and possible. As Hoopes (1981) notes,

Intercultural education consists of education activities which foster an understanding of the nature of culture, which helps the student develop 
skills in intercultural communication and which aids the student to view the world from perspectives other than one's own $(p, 6)$.

As noted earlier, ethnocentrism has been the basic medical approach to health problem-solving in southeast Alaska. Native values have infrequently been considered in program planning or individual counseling. However, rhetoric regarding "culturally relevant" health care is increasingly heard in medical and health groups and intercultural education for health professionals could insure a greater respect for values of others and a greater understanding of one's own.

Regarding intercultural communication training, Berry, Fodor, Ressler, and Wato (1983) note,

While course offerings in health science cover some aspects of intercultural and interpersonal communication, there is a need for a specific course that provides necessary intercultural and interpersonal communication skills. . . What is now needed is an on-going in-service training program in intercultural communication for those already in the field. In addition, program administrators must be educated as to the value of such skills training (p. 389).

The intercultural perspective is basic to intercultural education. And intercultural education should be basic to the medical and health training for health professionals. Such education is increasingly in demand, and with time and effort, culturally sensitive health care will result. 


\section{Summary}

This discussion has presented applications of the intercultural perspective to the four most frequently reported communication concerns of Natives. These concerns included condescending attitudes, authoritative approaches to counseling, learning style differences, and verbalization differences.

These concerns are problematic and their potential solutions are critical to this study's central theme, the communication of wellness. Without the mutual exchange of information and feelings, respect for style differences of dyadic members, and emphasis on the client's potential for health and healing, communication obstacles will continue to reduce the chances for the mutual creation of meaning. In addition, this chapter presents a statement encouraging health professionals to avail themselves of necessary training in the intercultural perspective. With time and increasing interest such education will be a basic part of medical/health training. 


\section{CHAPTER VI}

\section{SUGGESTIONS FOR FUTURE RESEARCH}

The following discussion presents future research areas generated by this study. This study has addressed some critical research areas, including investigation of cultural value differences between Natives and nonNatives, communication problems that result from such differences, Native indices for health, and cultural factors critical for non-Native competence as counselors. However, many questions are left unanswered.

This study has begun an investigation into the cultural values and life-styles of one small group of Alaskan Native people with a focus on how these factors affect the communication of wellness. As stated in the Arctic Health Science Policy's recommendations, it is critical to investigate these value differences and prevalence of positive health indicators as they exist in the Native population. The policy asserts that these indicators ". . may assist health planners to improve identification, and treatment efforts that are consistent with cultural factors" (American Public Health Association, 1981, p. 17). 
As a result of the data gathered by this thesis, many research areas surfaced. They included, but are not limited to, the following:

1. Field research in the area of transitional values of young Natives and how these values might influence the communication of wellness concepts.

2. Well-controlled validation testing of this study's modified HLC Scale.

3. Research into the development and implementation of health programs that utilize those social patterns and life-styles that seem to foster health and positive behaviors, giving consideration to cultural appropriateness in the communication of these concepts.

4. Research into the implementation of intercultural communication education within medical and nursing training programs.

5. Given the personal control over their health that Native interviewees perceived themselves to have, more research is needed regarding perceptions of non-Native health professionals regarding the expressed internality of their Native clients. 
As the Arctic Health Science Policy notes,

General discussions of social and behavioral aspects of health . - advance various hypotheses about the etiology of different diseases and concomitantly, the conditions that generate health. These hypotheses need to be more systematically explored (D. 12).

It is interesting to note that although this policy referred to culturally specific variables regarding health care, the actual communication of health concepts was not defined as a problem area. It is clear that the above quote is also applicable to the intercultural communication of wellness and prevention concepts. Hypotheses about the etiology of communication obstacles as well as the communication conditions that generate satisfying interactions between Native clients and non-Native health professionals are needed.

This study is hypotheses-generating. The following communication hypotheses have evolved from this study's discussion of social, behavioral, cultural, and communication aspects of wellness and health promotion concepts:

1. Ethnocentrism within health and medical settings is central to the major communication problems faced by Native clients as they interact with their non-Native health professionals.

2. Because ethnocentrism is an out-of-awareness phenomenon, intercultural communication education is required to encourage 
self-reflexiveness and cultural awareness in health professionals.

To summarize, further research is necessary to systematically test the hypotheses generated from this study. In what specific ways cultural value differences affect the communication of wellness concepts, how ethnocentrism creates frustrating communication problems, and what role intercultural communication education can play in modifying the ethnocentric perspective of medical and health professionals are research questions that require further systematic study.

This study is just a beginning. It provides a basis for further systematic investigations into practical areas, such as field research into the development and implementation of health programs that utilize the communication and cultural value factors addressed in this study.

As the Arctic Health Science Policy notes:

- . the circumpolar regions and populations might provide a particularly interesting and suitable avenue and subject of studies on 'positive health' or 'wellness.' The extreme conditions of the circumpolar areas provide an opportunity to test the validity of the positive health approach and, if applicable, the results might provide a starting point for encouraging the lifestyles and habits that promote health (American Public Health Association, 1981, p. 15).

As this study points out, Alaskan wellness programs currently exist and it is important for researchers to 
evaluate these programs, including how they are communicated. Wellness and positive health concepts are merely theories until they are communicated successfully within the Alaskan intercultural context. 
SELECTED BIBLIOGRAPHY

Albert, E. (1968). "Value System," International Encyclopedia of the Social sciences. (Vol. 9, pp 4-16). New York: MacMillan.

American Public Health Association, (1981). The National Arctic Health Science Policy.

Ardell, D. (1977). High Level Wellenss-Alternatives to Doctors, Drugs and Disease. CA.: Rodale Press.

Asante, M.K., Newmark, E., and Blake, C.A. (Eds.) (1979). Handbook of Intercultural Communication. Beverly Hills: Sage Publication.

Barna, L. (1982). "Stumbling Blocks in Intercultural Communication." In L. A. Samovar and R.E. Porter (Eds.), Intercultural Communication: A Reader. Belmont, CA.: Wadsworth Publishing Co., Inc.

Bennett, M.J. (1984). "Towards Ethno-relativism: A Developmental Model for Intercultural Sensitivity." Paper delivered at the Annual Conference of the Council on International Educational Exchange. Minneapolis, Minn.

Berry, E., Fodor, J.T., Kessler, J.B., and Wato, M. (1983). "Intercultural Communication for Health Personnel," International Journal of Intercultural Relations, 7:377-392.

Brislin, Richard w. (1981). Cross-Cultural Encounters. New York: Pergamon Press.

Carroll, C. (1982). Health--The Science of Human Adaptation. W.C. Brown Company Publishers.

Condon, J.C. and Yousef, F. (1980). An Introduciton to Intercultural Communication. Indianapolis: Bobb-Merrill Educational Publishing. 
Dauenhauer, R.L. (1980). Conflicting Visions in Alaskan Education. Unpublished manuscript, Alaska Pacific University, Anchorage, Alaska.

DeGross, D. (1980). The Alaska Native Health Board... Its past and Its Future. Published document by Alaska Native Health Board.

delaguna, F. (1972). Under Mount Saint Elias: The History of the Yakutat Tlingit. Washington, D.C.: Smithsonian Institute, vol. 1.

Drucker, P. (1965). Cultures of the North Pacific Coast. San Francisco, CA: Chandler Publishing Company.

Echohawk, M. (1977). "Leadership versus Behavioral Problems and Belief in Personal Control Among American Indian Youth," The Journal of Social Psychology, 102: 47-54.

Fortuine, R. (1975). "Health Care and the Alaska Native: Some Historical Perspectives," Polar Notes, XIV:1.

Good Tracks, J.G. (1973). "Native American Non-Interference," Social Work, Nov: 30-34.

Gurin, P., Gurin, G., Lao, R.C. and Beattie, M. (1969). "Internal-external control in the motivational dynamics of Negro youth," Journal of Social Issues, $25(3): 29-53$.

Hall, E.T. (1977). Beyond Culture. Garden City, NY: Anchor Press.

Hoopes, D.S. (1981). "Intercultural Communication Concepts and the Psychology of Intercultural Experience." In M. Pusch (Ed.), Multi-cultural Education. Chicago, IL.: Intercultural Network, Inc.

Ran, S. (1983). "Words that Heal the Soul: Analysis of the Tlingit Potlatch Oratory," Arctic Anthropology. $6(2): 2$.

Kluckhohn, C. (1951). "Values \& Value Orientations in the Theory of Action: An Exploration in Definition and Classification." In T. Parsons and E. A. Shils

(Eds.), Toward a General Theory of Action. Cambridge: Harvard University Press. 
Kluckhohn, F.R., and Strodtbeck, F.L. (1961). Variations in Value Orientations. New York: Harper and Row, Publishers.

Kohls, R. (1979). Survival Rit for Overseas Living. Chicago, IL.: Intercultural Press, Inc.

Kraus, R.F., and Duffler, P.A. (1979). "Sociocultural Stress and The American Native in Alaska: An Analysis of Changing Patterns of Psychiatric Illness and Alcohol Abuse Among Alaska Natives," Culture, Medicine and Psychiatry, 3:111-151.

Lantis, M. (1963). Acculturation and Health. (Al aska's Health, A Survey Report). Unpublished manuscript, University of Pittsburg, Graduate School of Public Health.

Manson, S., Tatum, E., and Dinges, N. (1982). "Prevention Research Among American Indian and Alaska Native Communities: Charting Future Courses for Theory and Practice In Mental Health." In S. Manson (Ed.), New Directions in Prevention Among American Indian and Alaska Native Communities. oregon Health Sciences University.

McClure, D. (1982). "Wellness: A Holistic Concept," Health Values: Achieving Hiah Level Wellness, 5:23-27.

McGregor, M. (1981). "Native Medicine in SE Alaska: Tsimshian, Tlingit, Haida," Alaska Medicine, (Nov./ Dec. ) : 65-69.

Oberg, Ralvervo, (1973). The Social economy of the Tlingit Indians. Seattle, WA: University of Washington Press.

Preamble A.N.B. Constitution, (1980, Summer). The Alaska Fisherman, p. 1 .

Rotter, J.B. (1966). "Generalized Expectancies for Internal Versus External Control of Reinforcement," Psychological Monographs, 80:1-28. 
Samovar, L. and Porter, R. (1982). Intercultural Communication: A Reader. Belmont, CA.: Wadsworth Publishing Co.

Sarbaugh, L.F. (1979). Intercultural Communication. New Jersey: Hayden Book Co.

Scollin, R. and Scollin, S.B.K. (1980). Interethnic Communication. Published by Alaska Native Language Center, University of Alaska.

Scollin, R. and Scollin, S.B.R. (1979). "Ethnic Stereotyping: Some Problems in Athabaskan-English Interethnic Communication," Alaska Court System Newsletter, 19:30.

Segal, B. (1983). "Alcohol and Alcoholism in Alaska: Research in a Multicultural and Transitional Society," The International Journal of the Addictions, $18(3): 379-392$.

Shephard, R. and Iton, S. (Eds.) (1974). "Circumpolar, Health, "International Symposium of Circumpolar Health, 2: 559-569.

Singer, M. R. (1982). "Culture: A Perceptual Approach." In L.A. Samovar and R.F. Porter (Eds.), Intercultural Communication: A Reader. Belmont, CA.: Wadsworth Publishing Co., Inc.

Southeast Alaska Regional Health Corporation, (1984). Tlingit Thinking: Lingit Tundataanee. Juneau, Alaska.

Stewart, E.C. (1972). American Cultural Patterns. Chicago, IL.: Intercultural Press, Inc.

Townes, C.D. (1984). "Wellness: Emerging Concept and Its Components," Individual Psychology, $40(4): 372-383$.

Triandis, H. C. (1972). The Analysis of Subjective Culture. New York: wiley/Interscience.

Trimble, J.E. and Richardson, S.S. (1982). "Locus of Control Measures Among American Indians," Journal of Cross-Cultural Psychology, 13(2): 228-238.

Tucker, R.K, Weaver, R.L., and Berryman-Fink, C. (1981). Research in Speech Communication. NJ.: PrenticeHall, Inc. 
Tyler, J.D. and Holsinger, D.N. (1975). "Locus of Control Differences Between Rural American Indian and White Children," The Journal of Social Psychology, 95: 149-155.

Tyler, L., Hall, P., and Taylor, J.S. (1981). "Intercultural Communication Data Acquisition." In M. Pasante, E. Newmark, and C. Blake (Eds.), Handbook of Intercultural Communication (Vol. 2). Beverly Hills: SY Publication, 1979.

U.S. Dept. of Interior, (1984). Alaska Native Settlement Act Study Draft. (Report No. 62).

U.S. Forest Service, (1984). The Subsistence Lifeway of the Tlingit People. (Report No. 131). Dept. of Agriculture, Alaska Region.

vaudrin, B. (1984). "Native/non-Native Communication: Creating A Two-Way Flow," Cultural Influences in Alaskan Native Education, 8: 6-10.

Vertinsky, P.I., Arango, J. and Scheverri, O. (1970). "Traditional Health Care Systems: Potentialities for Legitimization and Integration," International Journal of Health Education, $13(4): 142-148$.

Wallston, B.S., Wallston, K. A., Kaplan, G.D., and Maides, S.A. (1976). "Development and Validation of the Health Locus of Control (HLC) Scale," Journal of Consulting and Clinical Psychology, 4:580-585.

Waz, R.H. and Thomas, R.K. (1970). American Indians and White People. Unpublished manuscript. Available from [Author's address].

Wolfe, R.J. (1982). "Alaska's Great Sickness, 1900: An Epidemic of Measles and Influenza in Virgin Soil Population," Proceedings of the American Philosophical Society, $126(2): 91-121$. 
APPENDIX A

ORIGINAL INTERVIEW QUESTIONS 
ORIGINAL INTERVIEW QUESTIONS

1. What are the things you think are important in staying well?

2. What do you think are some characteristics of a healthy Native in today's society?

3. What do you think makes a person sick? or healthy?

4. What kinds of things did your grandparents tell you about staying well?

5. What do you think are the main differences between how a Native person and a non-native person thinks and feels about staying healthy?

6. What are some of the differences between traditional Native lifestyles and today's modern times that you think have influenced Native peoples' health?

7. When you get sick or have a physical problem, to whom do you go first? Friend, relative, the doctor or other health practitioner? Please explain.

8. Who do you consider to be healthy people in the Native community? Why?

9. What should non-native health professionals know about Natives and their culture to be good health counselors?

10. What are some of the things you like best about health professionals that you have known -- particularly in health counseling? What are some of the things you like least?

11. Who or what do you think is mostly responsible for a person's health. - . the doctor, clinic, a person's parents, God, "fate," or the individual person involved?

12. Have you ever been advised by a health practitioner that you should change some of your habits such as cigarette smoking or lowering your salt intake? If yes, please give an example. 
13. Have you ever been unable to understand what a health practitioner told you to do about a health problem?

14. Please describe an example of a health teaching situation you've been in and explain how it was or was not helpful.

15. Can you think of anything non-Native health professionals could do to be more helpful when they are counseling a Native client? 
APPENDIX B

FINALIZED INTERVIEW

SCHEDULE OF QUESTIONS 
1. What are some of the differences between traditional Native life styles and today's modern times that you think have affected Native health?

2. What do you think are some characteristics of a healthy Native person in today's society?

3. What should non-native health professionals know about Natives and their culture that would help them be better health counselors?

4. What are some of the things you like best about health professionals that you've known--particularly in health counseling situations.

5. What are some of the things you like least about health professionals that you've known--particularly in health counseling situations.

6. Who or what do you think is in control of a person's health? God, fate, luck, the person themselves, parents, or others?

7. Please give some exmaples of health teaching situations you've been in and explain how they have or have not been helpful. 
APPENDIX C

ORIGINAL HEALTH LOCUS OF CONTROL SCALE 
ORIGINAL HEALTH LOCUS OF CONTROL SCALE

Item

Direction

1. If I take care of myself, I can

avoid illness.

2. Whenever I get sick it is because of something I've done or not done.

I

3. Good health is largely a matter of good fortune.

E

4. No matter what I do, if I am going to get sick I will get sick.

E

5. Most people do not realize the extent to

$\mathbf{E}$ which their illnesses are controlled by accidental happenings.

6. I can only do what my doctor tells me to do.

E

7. There are so many strange diseases around that you can never know how or when you might pick one up.

E

8. When I feel ill, I know it is because I have not been getting the proper exercise or eating right.

9. People who never get sick are just plain lucky.

10. People's health results from their own carelessness.

11. I am directly responsible for my health. I

$I=$ internally worded. $E=$ externally worded. The scale is scored in the external direction, with each item scoring from 1 (strongly disagree) to 6 (strongly agree) for the externally worded items and reverse scored for the internally worded (Walston et al. 1976, p. 580). 
APPENDIX D

MODIFIED HEALTH LOCUS OF CONTROL QUESTIONNAIRE USED IN THIS STUDY 


\section{Health Locus of Control Questions}

Dear Participants

Please answer the following questions with "yes" or "no." I realize these are hard to answer in that way. But whatever you usually or most often feel or do should direct your answer.

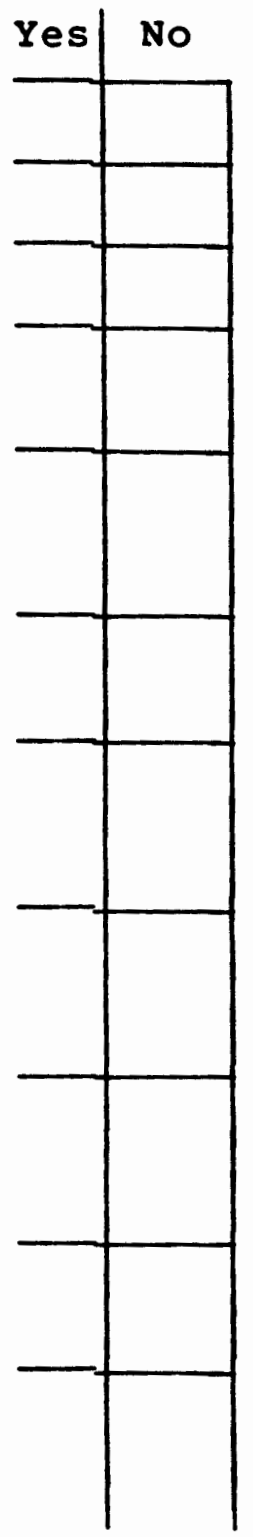

1. Do you think that if you take care of yourself you cn avoid most illnesses?

2. When you get sick do you usually think it is because of something you have or have not done for your health?

3. Do you think good health is mostly a matter of good fortune?

4. Do you think the following sentence is true? "No matter what I do, if I am going to get sick I will get sick."

5. When you are ill and go to the doctor do you think you should only do what the doctor tells you to do?

6. Do you think that there are so many strange diseases around now that you really never know how or when you might get sick?

7. When you feel ill, do you think it is because you haven't been getting the proper exercise, or rest or righty food, etc?

8. Do you think that people who never get sick are just plain lucky?

9. Do you think iliness is usually a result of a person's own carelessness?

10. Do you think you are directly responsible for your own health?

Please comment if you wish:

November 6,1984 for Janet Allan's Thesis Project 
APPENDIX E

HEALTH LOCUS OF CONTROL SCALE RESULTS 
MODIFIED HEALTH LOCUS OF CONTROL SCALE RESULTS

\begin{tabular}{|c|c|c|c|c|}
\hline & & $\begin{array}{l}\text { ive } \\
\text { Ith } \\
\text { iders }\end{array}$ & $\begin{array}{l}\text { Non- } \\
\text { Heal } \\
\text { Prov }\end{array}$ & \\
\hline & Yes & No & Yes & No \\
\hline $\begin{array}{l}\text { 1. Do you think that if } \\
\text { you take care of your- } \\
\text { self you can avoid most } \\
\text { illness? }\end{array}$ & 9 & 1 & 7 & 3 \\
\hline $\begin{array}{l}\text { 2. When you get sick do } \\
\text { you usually think it is } \\
\text { because of something } \\
\text { you have or have not } \\
\text { done for your health? }\end{array}$ & 9 & 1 & 9 & 1 \\
\hline $\begin{array}{l}\text { 3. Do you think that } \\
\text { good health is mostly } \\
\text { a matter of good } \\
\text { fortune? }\end{array}$ & 1 & 9 & 1 & 9 \\
\hline $\begin{array}{l}\text { 4. Do you think this } \\
\text { sentence is true: "No } \\
\text { matter what I do, if } \\
\text { I'm going to get sick } \\
\text { I will get sick." }\end{array}$ & & 10 & 2 & 8 \\
\hline $\begin{array}{l}\text { 5. When you are ill and } \\
\text { go to the doctor do you } \\
\text { think you should only } \\
\text { do what the doctor } \\
\text { tells you to do? }\end{array}$ & 1 & 9 & 2 & 8 \\
\hline $\begin{array}{l}\text { 6. Do you think that } \\
\text { there are so many } \\
\text { strange diseases around } \\
\text { now that you really } \\
\text { never know how or when } \\
\text { you might get sick? }\end{array}$ & 7 & 3 & 3 & 7 \\
\hline $\begin{array}{l}\text { 7. When you feel ill, } \\
\text { do you think it is be- } \\
\text { cause you haven't been } \\
\text { getting the proper } \\
\text { exercise, or rest, or } \\
\text { right food, etc.? }\end{array}$ & 8 & 2 & 4 & 6 \\
\hline
\end{tabular}




\begin{tabular}{l|c|cc} 
& $\begin{array}{c}\text { Native } \\
\text { Health } \\
\text { Providers }\end{array}$ & $\begin{array}{l}\text { Non-Native } \\
\text { Health } \\
\text { Providers } \\
\text { No }\end{array}$ & Yes No \\
\hline $\begin{array}{l}\text { 8. Do you think that } \\
\text { people who never get } \\
\text { sick are just plain } \\
\text { lucky? }\end{array}$ & 1 & 9 & 1 \\
\hline $\begin{array}{l}\text { 9. Do you think illness } \\
\text { is usually a result of } \\
\text { a person's own care- } \\
\text { lessness? }\end{array}$ & 8 & 2 & 9 \\
\hline $\begin{array}{l}\text { 10. Do you think you } \\
\text { are directly responsi- } \\
\text { ble for your own } \\
\text { health? }\end{array}$ & 10 & & 7 \\
(10) Total subjects & & 9 & 1 \\
\hline
\end{tabular}

Native Health Providers consisted of 3 Health Aids, 3 Alcoholism Counselors, 1 Emgergency Medical Technician, 1 Health Mediator, 1 Child Counselor, 1 Health Instructor.

(10) Total Subjects

Non-Native Health Providers consisted of 4 M.D.'s 3 R.N.'s, 1 Counselor, 1 Dentist and 1 Emergency Medical Instructor. 
APPENDIX F

SEARHC HEALTH FAIR FORMS 


\section{CONFIDENTIAL HEALTH HISTORY}

ITICIPANT INSTRUCTIONS: Each question must be answered Yes or NO. DO NOT skip any. Numbers in parentheses (230) are for ing purposes only.

i. Have you ever been treated for.

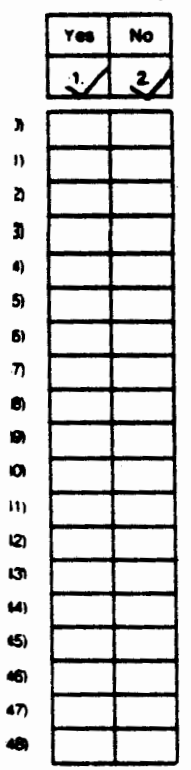

Anemia (low blood count)

Cancer

Diabetes

Fibrocystic disease

Glaucoma

Gout

Hearing problems

Heart disease

High Blood Pressure

High cholesterol

High triglycerides

Kidney disease (chronic)

Liver disease

Lung disease (includes TB)

Polyps or growth in bowels

Thyroid disease

Vision problem (NOT glasses)

Weight problem

Other
16. Have any of your blood relatives ever had:

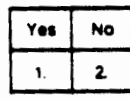

Diabetes .............................

Heart attack..........................

High cholesterol....................... (xs)

High blood pressure.....................

Cancer...............................

Glaucoma .......................... eso

Mental/Emotional Stress .................

Alcohol or other drug problems .............

17. These are the seven warning signs of cancer

Have you noticed any:

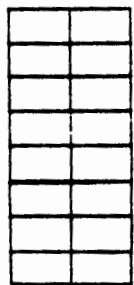

Unusual bleoding or discharge

Nagging hoarseness or cough.

Obvious change in a mole or wart................

Persistant indigestion or difficulty in swallowing.... .

Lump or thickening in breast of elsewhere.......... Change in bowel or bladder habits............... Trouble with sores healing. ..............

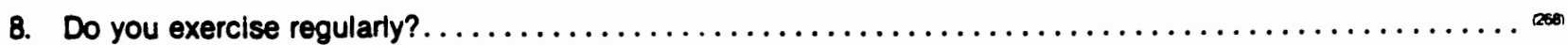

9. Do you diet regularly or frequently?.

20

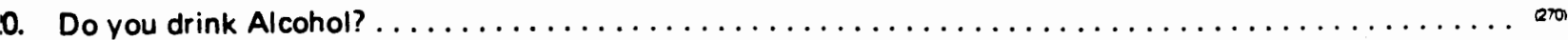

11. Do you have shortness of breath, pain, or discomfort in the chest after exercise? $\ldots \ldots \ldots \ldots \ldots \ldots \ldots{ }^{2711}$

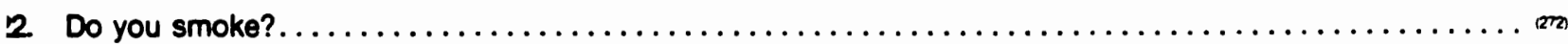
If YES, how many per day? cigarettes cigars pipe

23. Are you under stress much of the time at home or work?

24. Are you satisfled with your current lifestyle/habits? 272,

25. Do you have a personal doctor or regular source of medical care? 275;

26. Are you currently being treated for an illness?. If YES, what illness are you being treated for

27. Are you currently taking any medications?. If YES, what medications are you currently taking

28. Have you made a change in your lifestyle in the last year to improve your health? What change?

29. Who has the major responsibility for your health? $\frac{1}{3}$ doctor (check only one)

OPTIONAL: The following information helps determine the community we serve.

\section{RACIAL GROUP}

(check onty one)

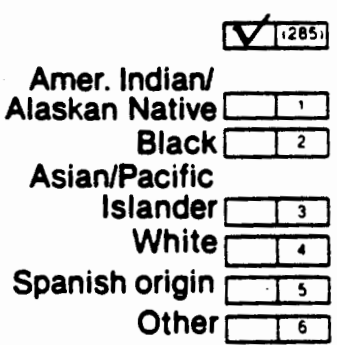

\section{FAMILY INCOME}

$$
\text { (check onty one) }
$$

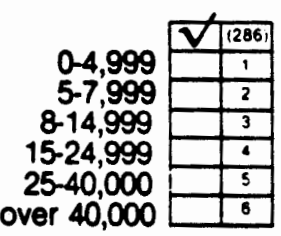

32. EMPLOYMENT STATUS

(check only ore)

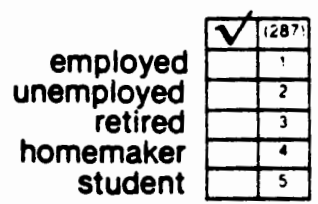

33. MARITAL STATUS

(check onty one)

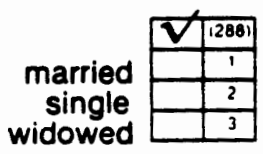

34. LAST GRADE COMPLETED [Please enter number (II)]

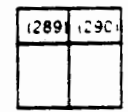


Jate

Health Fair Location

Thank you for particlpating. To improve Health Fairs we need to know how you feel about them and would greatly appreciate your inswering these questions. Numbers in parenthesis (20) are for coding purposes only. Please check only One box for each answer inless instructed otherwise.

1. How would you rate the Health Fair in general?. . . . . (11)

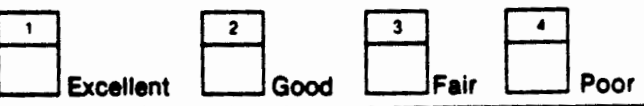

2. Would you go to another Health Fair or recommend one to a friend or relative?.

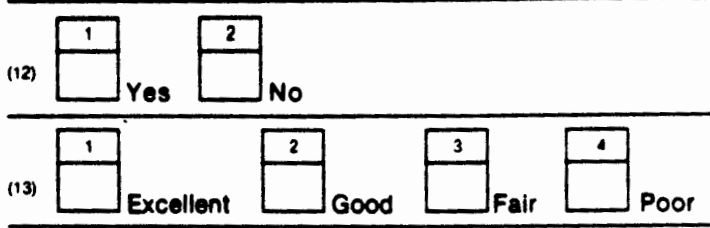

4. Did the examiners explain the purpose of the tests?.

5. Did you understand the explanation of the tests?...

6. Did you leam anything about changing your habits to

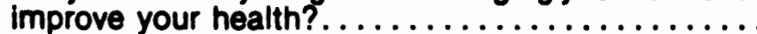

7. Why did you come to the Health Fair? (check as many as apply).......................

8. How did you hear about the Health Fair? (check as many as apply)................ (25)
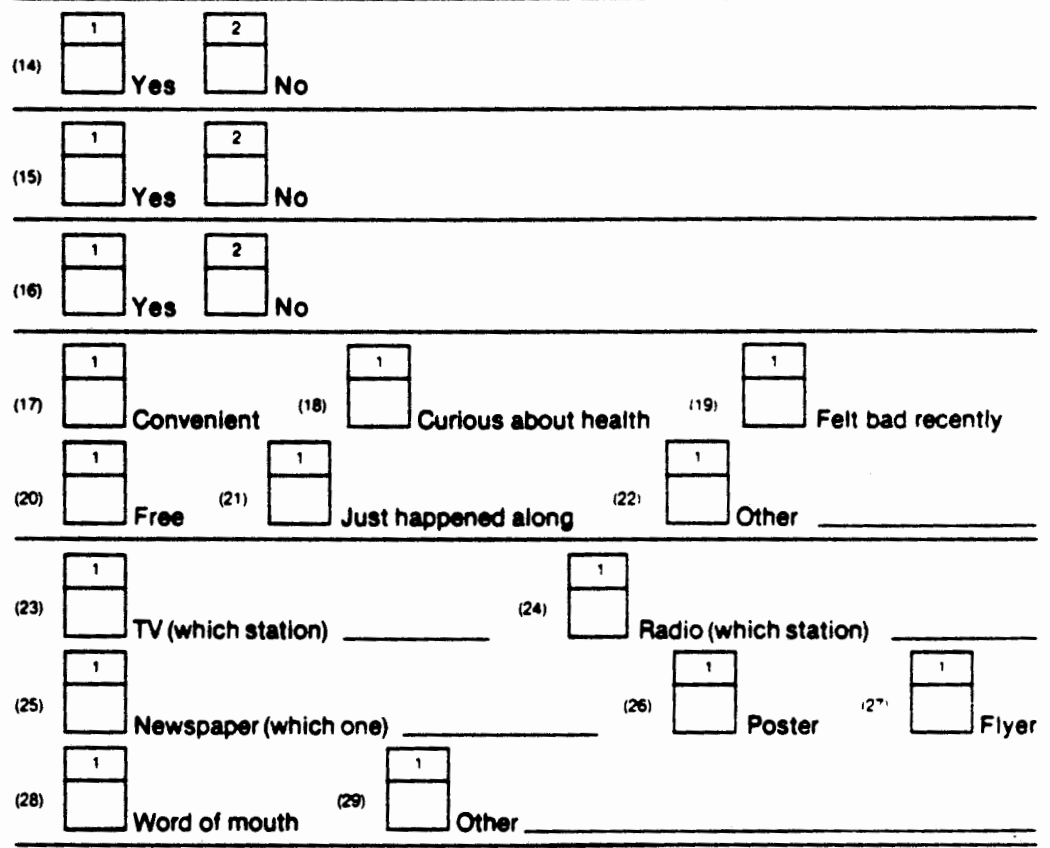

9. Have you ever received ALL THE SERVICES at this health fair anywhere else at one time?............

If so, where? (check one only)............

10. Were there any exhibits, demonstrations, or activities which you found particularly helpful or interesting? Which ones:

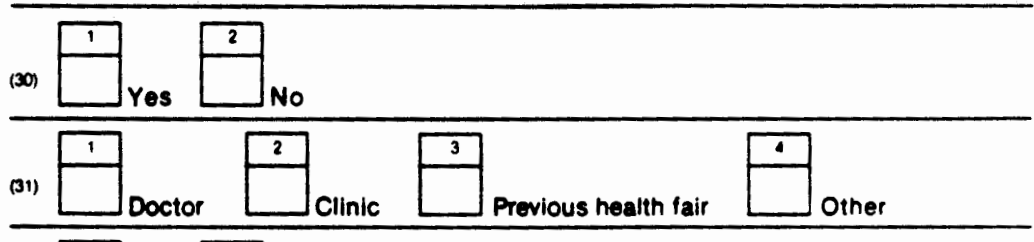

11. Whotras the major responsibility for your health?

12. Did your counselor advise you to get a follow-up evaluation on any of your tests?.

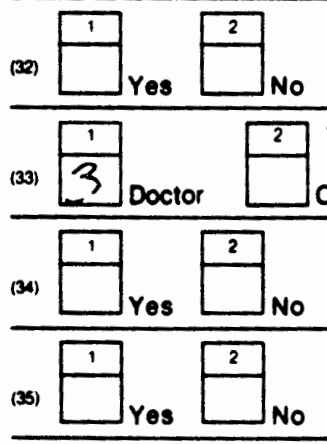

14. When was the last time you saw a doctor?........

15. When was the last time you had a complete chock-up WHEN YOU WERE NOT SICK?................

16. If you do not get a further follow-up evaluation on tests outside nomal limits do you understand how your decision may affect your future health?

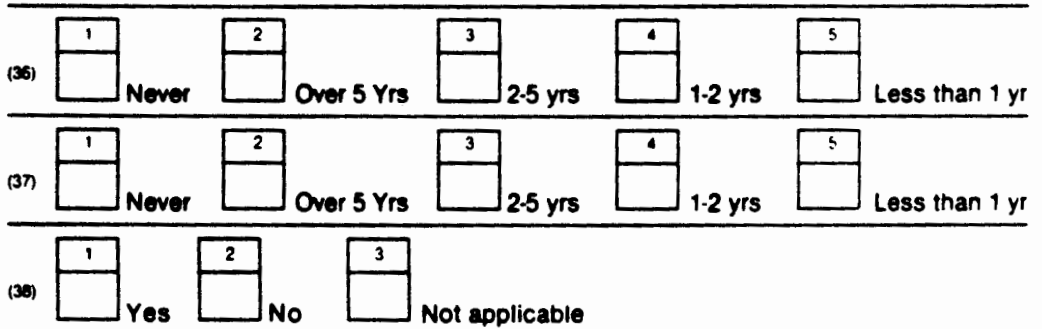

17. COMMENTS (bad and good equally welcomed) 